\title{
Misallocation and Productivity in the Lead Up to the Eurozone Crisis
}

Dias, Daniel A., Carlos Robalo Marques, and Christine Richmond
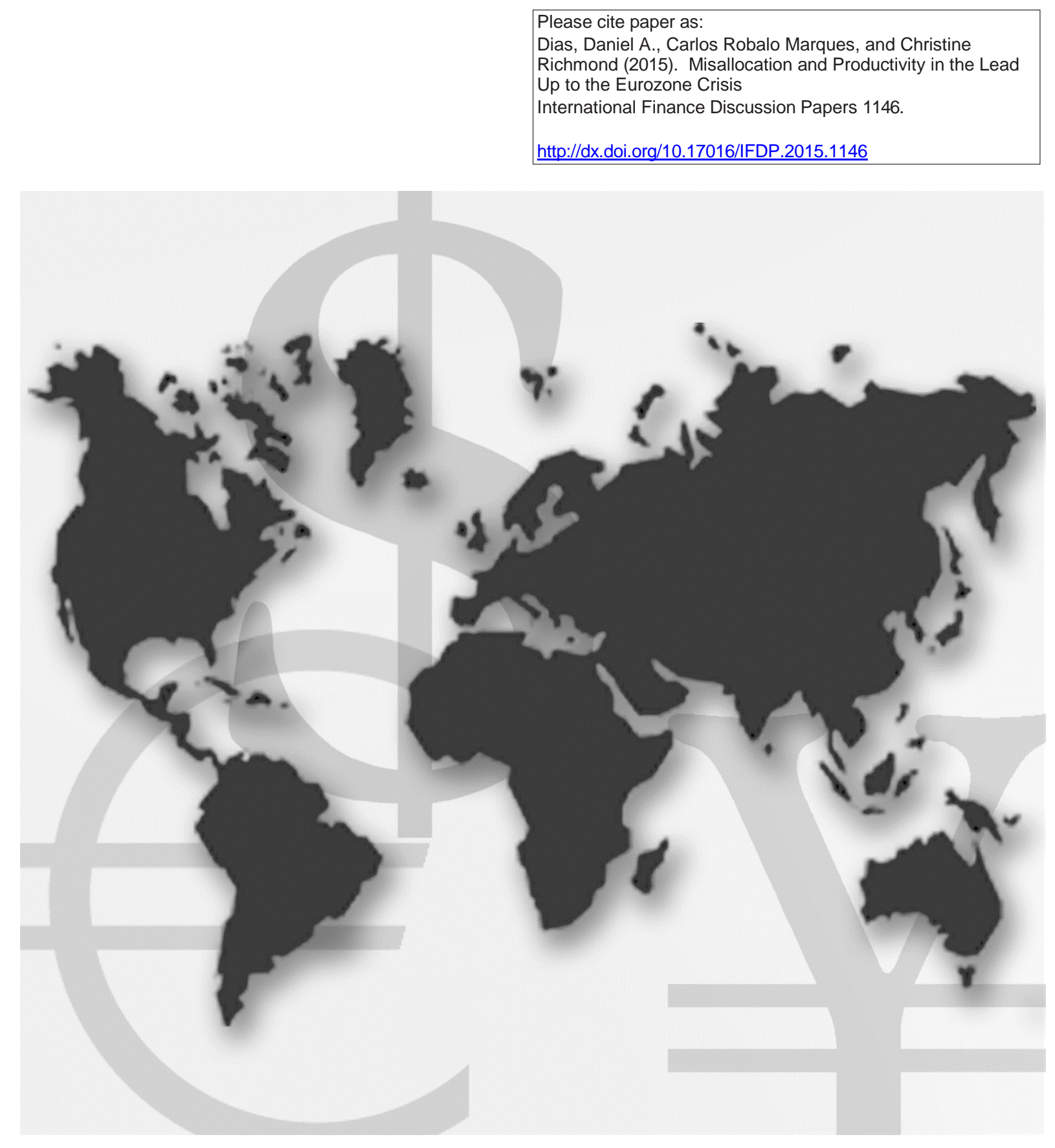

\section{International Finance Discussion Papers}

Board of Governors of the Federal Reserve System

Number 1146

September 2015 


\title{
Board of Governors of the Federal Reserve System \\ International Finance Discussion Papers
}

Number 1146

September 2015

\section{Misallocation and Productivity in the Lead Up to the Eurozone Crisis}

\author{
Daniel A. Dias \\ Carlos Robalo Marques \\ Christine Richmond
}

NOTE: International Finance Discussion Papers are preliminary materials circulated to stimulate discussion and critical comment. References to International Finance Discussion Papers (other than an acknowledgment that the writer has had access to unpublished material) should be cleared with the author or authors. Recent IFDPs are available on the Web at www.federalreserve.gov/pubs/ifdp/. This paper can be downloaded without charge from the Social Science Research Network electronic library at www.ssrn.com. 


\title{
Misallocation and Productivity in the Lead Up to the Eurozone Crisis*
}

\author{
Daniel A. Dias, Carlos Robalo Marques ${ }^{\ddagger}$ and Christine Richmond ${ }^{\S}$
}

September 3, 2015

\begin{abstract}
We use Portuguese firm-level data to investigate whether changes in resource misallocation may have contributed to the poor economic performance of some southern and peripheral European countries leading up to the Eurozone crisis. We extend Hsieh and Klenow's (2009) methodology to include intermediate inputs and consider all sectors of the economy (agriculture, manufacturing, and services). We find that within-industry misallocation almost doubled between 1996 and 2011. Equalizing total factor revenue productivity across firms within an industry could have boosted valued-added 48 percent and 79 percent above actual levels in 1996 and 2011, respectively. This implies that deteriorating allocative efficiency may have shaved around 1.3 percentage points off the annual GDP growth during the 1996-2011 period. Allocative efficiency deterioration, despite being a widespread phenomenon, is significantly higher in the service sector, with 5 industries accounting for 72 percent of the total variation. Capital distortions are the most important source of potential value-added efficiency gains, especially in the service sector, with a relative contribution increasing over time.
\end{abstract}

JEL classification: D24, O11, O41, O47

Key words: Misallocation, wedges, productivity, firm-level data, financial integration.

${ }^{*}$ We thank seminar participants at Banco de Portugal, Federal Reserve Board of Governors, UIUC Agriculture and Consumer Economics, Eighth North American Productivity Workshop and Chris Sims and Mark Wright for helpful discussions at various stages in this project. The analyses, opinions and findings of this paper represent the views of the authors, which are not necessarily those of Banco de Portugal, the Eurosystem, the IMF, or IMF policy, the Board of Governors of the Federal Reserve System or of any other person associated with the Federal Reserve System.

${ }^{\dagger}$ Board of Governors of the Federal Reserve System and CEMAPRE. Email: daniel.dias@frb.gov

¥Banco de Portugal (Research Department). E-mail address: cmrmarques@bportugal.pt

$\S$ International Monetary Fund. E-mail address: crichmond@imf.org 


\section{Introduction}

Financial integration of the Eurozone was supposed to improve resource allocation efficiency, facilitate risk sharing, and boost economic growth. By 2004 the European Central Bank and European Commission concluded that money markets were well integrated, government bond yields were rapidly converging, there was a reduction in the home bias of bond portfolios, and equity markets were deepening (Baele et al. (2004)). But this financial integration has not necessarily translated into higher growth or productivity for some southern and peripheral European countries, which have experienced stagnant or declining productivity and a loss of competitiveness, despite large capital inflows in the decade preceding the onset of the Eurozone crisis in 2009 (see Figure 1) 1

In this paper, we investigate whether changes in resource misallocation may have contributed to the poor economic performance of some southern and peripheral European countries leading up to the Eurozone crisis. More specifically, we want to understand if, over time, there were changes in the degree of allocative efficiency of resources, which could have led to a significant decline in total factor productivity (TFP) and GDP growth, and when changes occurred, what may explain them.

To answer these questions, we study the evolution of resource misallocation in the Portuguese economy during the period 1996 to 2011 using firm-level data. Portugal is an interesting case study since substantial resources were channeled to the country beginning in the mid-1990s by both official and private sources, and it raises the question of whether these resources were properly allocated.2 We use Hsieh and Klenow (2009)

\footnotetext{
${ }^{1}$ Note that in contrast to what happened in the 5 southern and peripheral countries in Figure 1, most northern Eurozone countries like Germany, France, Finland and the Netherlands experienced TFP gains up until 2008. For details on the TFP computations, see http://www.conference-board.org.

${ }^{2}$ Between 1995 and 2001 the Portuguese economy benefited from the Eurozone convergence in the run-up to the introduction of the euro, undergoing a structural transformation, shifting away from manufacturing and towards services. However, this came at the expense of competitiveness and higher indebtedness. By 2002, investment and GDP had stagnated, but large current account and headline budget deficits remained, resulting in general government debt breaching $60 \%$ of GDP in 2004 . The whole situation deteriorated further in the following years. By 2010, the interest rates on long-term Portuguese government bonds started rising, a few months after the same had happened in Greece. By April 2011 the Portuguese government was forced to ask for external assistance. One month later, the troika comprised of the International Monetary Fund, European Commission and European Central Bank approved a memorandum of understanding with the Portuguese government in exchange for a
} 

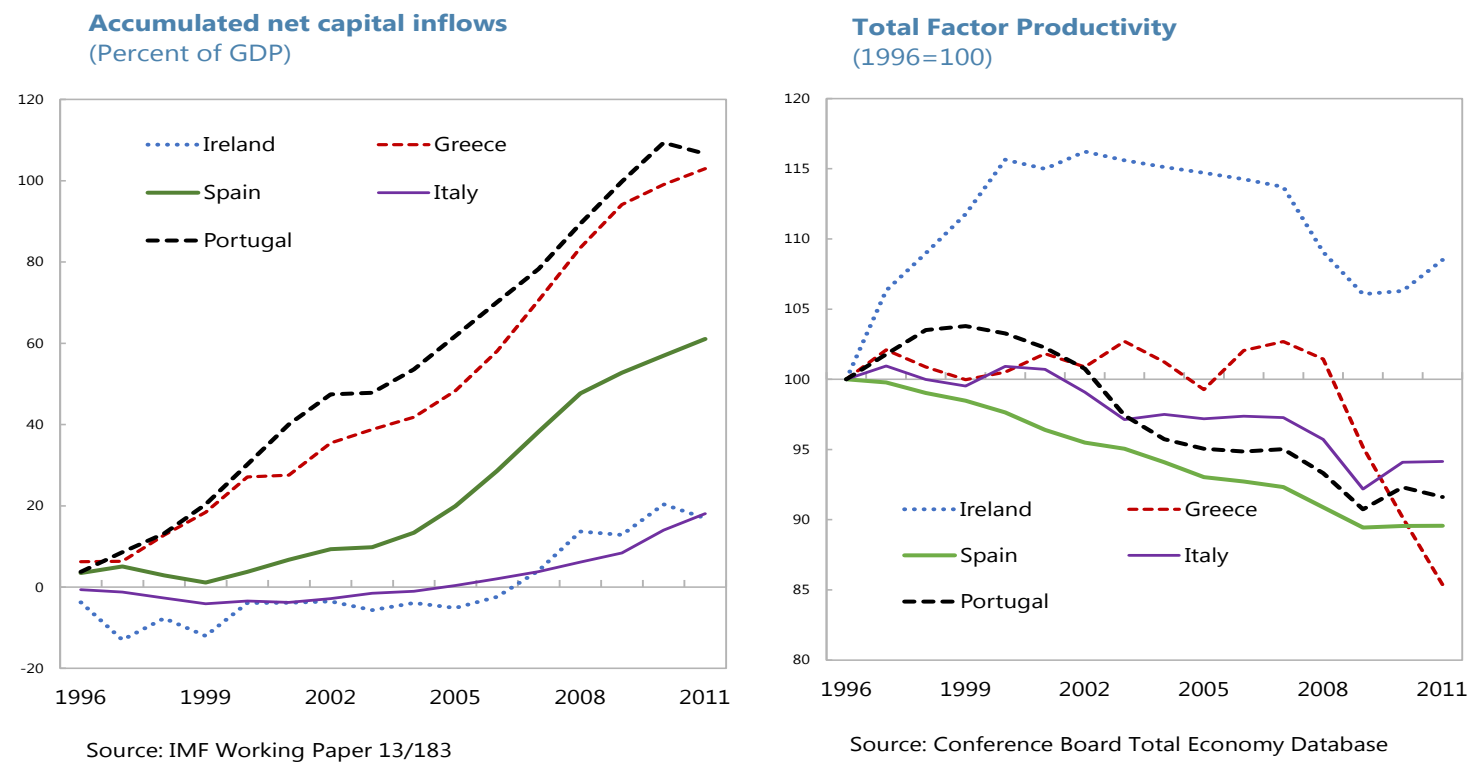

Figure 1: Net capital inflows and TFP

methodology of a simple structural model to quantify the costs of resource misallocation for productivity and GDP growth but instead consider a 3-factor production function defined on gross output. This is important since, as Jones $(2013)$ notes, misallocation may be even higher if one allows for reallocation of intermediate inputs. We extend the analysis to consider all sectors of the economy (agriculture, manufacturing, and services). We believe this is important given the sizeable role of services in economic output and employment in developed countries today. By focussing on the 1996-2011 period, we also investigate how misallocation has evolved during a period of structural transformation and in the run-up to a crisis.

Recently, Reis (2013) in searching for the causes of the Portuguese economic slump of the 2000's argued that certain characteristics of Portugal's financial sector caused the capital inflows to be largely misallocated, leading to an expansion in the country's relatively unproductive nontradables sector, and thus to a fall in measured productivity. This explains why, in his view, the case of Portugal is unique in the sense that it rescue package. See Blanchard (2007) and Reis (2013) for detailed analyses of the evolution of the Portuguese macroeconomy in the run-up to the Eurozone crisis. 
was the only country where GDP stagnated, while Greece, Ireland and Spain enjoyed a boom. Our paper also looks at resource misallocation but departs from Reis (2013) in some important dimensions. First, we do not assume that the case of Portugal is essentially distinct from the other southern and peripheral Eurozone economies because, as Figure 1 shows, they all display stagnant or decreasing productivity during the 2000 's in contrast to other northern Eurozone countries where productivity increased. Second, while Reis (2013) looks at between-sector misallocation, we use firm-level data to investigate the evolution of within-industry resource misallocation and its implications for potential Portuguese TFP and GDP growth. Finally, our methodological approach allows us to identify the relative importance of the distortions prevailing in the economy and their negative implications for TFP growth, including not only capital distortions, but also labor and output distortions.

We find that within-industry misallocation almost doubled between 1996 and 2011 in Portugal. Fully equalizing total factor revenue productivity (TFPR) across firms in each industry, thereby reallocating resources away from the least towards the most efficient firms, would have increased gross output by 17 percent in 1996 and 28 percent in 2011. In terms of aggregate value added, output would have been 48 percent and 79 percent above actual GDP levels in 1996 and 2011, respectively. These figures imply that deteriorating allocative efficiency may have shaved around 0.6 percentage points (pp) off annual gross-output growth and $1.3 \mathrm{pp}$ off annual GDP growth during the 1996-2011 period. These are large figures as Portuguese GDP grew, on average, 1.5 percent per year over this period. The results are driven by the service sector, whose levels of misallocation are significantly higher and increased much faster than those of the manufacturing sector.

Allocative efficiency deterioration during the sample period is a widespread phenomenon, but the relative contributions differ significantly across industries. We observe a high concentration in just a few industries of the service sector, with 5 industries accounting for 72 percent of the total increase in resource misallocation. 
Capital distortions emerge as more important than labor and output distortions in explaining potential value-added efficiency gains, especially in the service sector. Eliminating variation in the capital wedge implies value-added gains for the whole economy of 18 percent in 1996 and 32 percent in 2011. Furthermore, their relative contribution to total efficiency gains increased over time, from 46 percent in 1996 to 55 percent in 2011.

Smaller firms appear as having, on average, benefitted from capital and labor subsidies. This suggests that a large proportion of firms may have survived because they had access to cheap credit and labor, either because of firm size-contingent laws passed by the Portuguese Government, that directly or indirectly reduced the costs of inputs for these firms, or because they managed to evade taxes or circumvent some general labor and/or capital regulations.

Our paper contributes to the literature on the role of resource misallocation in explaining aggregate productivity and income per capita differences across countries. Following the work of Hsieh and Klenow (2009), who analyze manufacturing sectors in the U.S., China, and India, several applications to other countries have concluded that misallocation can be responsible for significant aggregate GDP losses.$^{3}$ Within this literature, some papers are interested in understanding the consequences of financial crises on output and productivity (see, for example, Benjamin and Meza (2009), Sandleris and Wright (2011), Hallward-Driemeier and Rijkers (2011), Chen and Irarrazabal (2013), and Oberfield (2013)). These papers tend to find that during a crisis, relatively more productive firms will exit but at the same time, entering firms are more productive. While in the aftermath of a crisis, allocative efficiency improves with a reduction in the cross-sectional dispersion of output distortions. ${ }^{4}$

\footnotetext{
${ }^{3}$ See, for instance, Chen and Irarrazabal (2013) for Chile, Machicado and Birbuet (2012) for Bolivia, Camacho and Conover (2010) for Colombia, and Busso et al. (2012) for some Latin America countries. The only known exception is the contribution by Bellone and Mallen-Pisano (2013) for France that concludes that misallocation in the manufacturing sector is lower than in the U.S..

${ }^{4}$ Recently, Foster et al. (2013) investigating reallocation in the U.S. during the Great Recession conclude that the intensity of reallocation fell rather than rose and that the reallocation that took place was less productivity enhancing than in prior recessions.
} 
More generally, our paper is related to the literature on international financial integration. According to the standard neoclassical growth model, financial integration facilitates the flow of capital to capital-scarce countries, having positive output and productivity effects (see Acemoglu and Zilibotti (1997) or Bonfiglioli (2008)). While indirect benefits from financial integration can positively impact TFP growth by leading to a more efficient allocation of resources (Kose et al. (2009)), others have suggested that financial integration in the presence of distortions will have negative output consequences (see Boyd and Smith (1992), Eichengreen (2001), or Edison et al. (2002)). More recent work on the importance of financial frictions suggests that they can account for a large portion of the observed cross-country differences in aggregate TFP, sector-level relative productivity, and per capita output (see Buera et al. (2011)). Our results are consistent with the findings that in the presence of distortions, financial integration may not contribute to large output gains or can even lead to output losses.

The rest of the paper is structured as follows. Section 2 provides details about the methodology. Section 3 describes the data used in our analysis. Section 4 presents the empirical findings. Section 5 provides some robustness checks. Section 6 discusses the type of distortions prevailing in the Portuguese economy and section 7 concludes. Appendices provide the derivation of formulas and a comparison of misallocation to the U.S. and other countries for which comparable numbers are available.

\section{Theoretical framework}

This section describes the methodology used to identify the linkage between aggregate productivity, aggregate value added and resource misallocation that results from the existence of distortions and frictions affecting the optimal allocation of factors of production at the firm-level. We adopt the framework developed in Hsieh and Klenow (2009, 2011), but extend their model to consider a production function with intermediate inputs, as a third factor of production. This three-factor production function exten- 
sion allows us to investigate resource misallocation by looking not only at firms' gross output, but also at firms' value added, with the important advantage that identified value-added efficiency gains are consistent with the efficient allocation of intermediate inputs, something that is not guaranteed by the two-factor model approach used so far in the literature.

Let us assume an economy with a single final good $Y$ produced by a representative firm in a perfectly competitive market. This firm combines the output $Y_{s}$ of $S$ industries in the economy using a Cobb-Douglas production technology:

$$
Y=\prod_{s=1}^{S}\left(Y_{s}\right)^{\theta_{s}}
$$

with $\sum_{s=1}^{S} \theta_{s}=1$. Cost minimization implies that industry shares, $\theta_{s}$, are given by:

$$
\theta_{s}=\frac{P_{s} Y_{s}}{P Y}
$$

where $P_{s}$ is the price of industry gross output, $Y_{s}$, and $P$ is the price of the final good. The final good $Y$ is assumed to be the numeraire so that we can set $P=1$.

At the industry level, gross output $Y_{s}$ is a CES aggregate of $M_{s}$ differentiated products:

$$
Y_{s}=\left[\sum_{i=1}^{M_{s}}\left(Y_{s i}\right)^{\frac{\sigma-1}{\sigma}}\right]^{\frac{\sigma}{\sigma-1}}
$$

where $Y_{s i}$ stands for the gross output of firm $i$ and parameter $\sigma$ measures the elasticity of substitution between varieties of differentiated goods. The assumptions of free entry and monopolistic competition at the industry level imply inverse demand equations for each individual variety equal to:

$$
P_{s i}=Y_{s}^{\frac{1}{\sigma}} P_{s}\left(Y_{s i}\right)^{\frac{-1}{\sigma}}
$$


In equation (41), the term $Y_{s}^{\frac{1}{\sigma}} P_{s}$ is not observed, so that we set it equal to 1 for each industry $s .^{5}$ This assumption has no practical implications for the exercise. It does not affect relative productivities and hence reallocation gains since we do not consider interindustry reallocation.

At the firm level, the gross output for each differentiated product is given by a Cobb-Douglas production function:

$$
Y_{s i}=A_{s i} K_{s i}^{\alpha_{s}} H_{s i}^{\beta_{s}} Q_{s i}^{1-\alpha_{s}-\beta_{s}}
$$

where $A_{s i}, K_{s i}, H_{s i}$ and $Q_{s i}$, stand for firm $i^{\prime} s$ total factor productivity, capital stock, labor and intermediate inputs, respectively. Note that factor shares can vary across industries but not across firms within the same industry.

With three factors of production it is possible to separately identify distortions that affect capital, labor and intermediate input prices simultaneously from distortions that affect the marginal product of one of the factors relative to the others. Thus, we introduce three types of distortions, or wedges, in the model: an output distortion, denoted $\tau_{y_{s i}}$, a capital distortion, $\tau_{k_{s i}}$, and a labor distortion, $\tau_{h_{s i}}$, that take a form of a tax on revenues, a tax on capital services and a tax on labor costs, respectively. Given these assumptions, profits are given by

$$
\pi_{s i}=\left(1-\tau_{y_{s i}}\right) P_{s i} Y_{s i}-\left(1+\tau_{k_{s i}}\right) R_{s} K_{s i}-\left(1+\tau_{h_{s i}}\right) W_{s} H_{s i}-Z_{s} Q_{s i}
$$

where $R_{s}, W_{s}$ and $Z_{s}$ stand for the user cost of capital, labor wage and intermediate inputs price, respectively. Equation (6) warrants some explanations. The output wedge denotes any distortion that changes the marginal products of capital, labor and intermediate inputs by the same proportion. For example, $\tau_{y}$ is expected to be high for firms that face restrictions on size and low in firms that benefit from government

\footnotetext{
${ }^{5}$ This is equivalent to assuming $\kappa_{s}=\frac{\left(Y_{s} P_{s}\right)^{-\frac{1}{\sigma-1}}}{P_{s}}=1$, which is the assumption made in Hsieh and Klenow (2009, 2011).
} 
subsidies. In turn, the capital and labor wedges denote any distortion that raises the marginal product of capital or of labor relative to the marginal product of intermediate inputs. For example, $\tau_{k}$ will be high for firms that do not have access to credit and low for firms with access to cheap credit ${ }^{6}$

Equation (6) expresses the distortions in terms of output, capital and labor relative to the intermediate inputs distortion. Thus, in the model, an intermediate input distortion will show up as a higher output distortion and as lower capital and labor market distortions $\sqrt{7}$

Profit maximization yields the standard conditions that the firm's output price is a fixed markup over marginal cost:

$$
P_{s i}=\frac{\sigma}{\sigma-1} \Psi_{s} \frac{\left(1+\tau_{k_{s i}}\right)^{\alpha_{s}}\left(1+\tau_{h_{s i}}\right)^{\beta_{s}}}{A_{s i}\left(1-\tau_{y_{s i}}\right)}
$$

where

$$
\Psi_{s}=\left[\left(\frac{R_{s}}{\alpha_{s}}\right)^{\alpha_{s}}\left(\frac{W_{s}}{\beta_{s}}\right)^{\beta_{s}}\left(\frac{Z_{s}}{1-\alpha_{s}-\beta_{s}}\right)^{1-\alpha_{s}-\beta_{s}}\right]
$$

\footnotetext{
${ }^{6}$ The list of policies that may generate firm-level distortions is long and varied. For instance, noncompetitive banking systems may offer favourable interest rates on loans to some producers based on non-economic factors, leading to a misallocation of credit across firms. Or, financial institutions may be unable or unwilling to provide credit to firms that are highly productive but have no credit history or insufficient guarantees, preventing these firms from expanding their activities. Governments may offer subsidies, special tax deals or lucrative contracts to specific producers. Various product and labor-market regulations may drive up the cost of labor in the formal vis-à-vis the informal sector, or in big versus small firms, or drive down the cost of capital in small firms (through special lines of credit). Enforcement activity of tax collection may focus on large and most productive firms implying a subsidy to small potentially less productive ones.

Besides distortions on the prices of inputs, wedges may also be interpreted as a stand-in for all of the costs of hiring factors beyond the market price of the factor itself (frictions). Thus, they may also capture the presence of adjustment costs to varying factors or the effect of rationing due to quantity restrictions, for instance. Since in the context of our empirical strategy, we cannot separately identify the impact of distortions and frictions, we generally use the term distortion to refer to the combination of both.

${ }^{7}$ An observationally equivalent characterization would be in terms of distortions to the absolute levels of capital, labor and intermediate input prices (and no output distortion).
} 
In turn, from the first order conditions for profit maximization, we get:

$$
\begin{aligned}
\left(1+\tau_{k_{s i}}\right) & =\frac{\alpha_{s}}{\left(1-\alpha_{s}-\beta_{s}\right)} \frac{Z_{s} Q_{s i}}{R_{s} K_{s i}} \\
\left(1+\tau_{h_{s i}}\right) & =\frac{\beta_{s}}{\left(1-\alpha_{s}-\beta_{s}\right)} \frac{Z_{s} Q_{s i}}{W_{s} H_{s i}} \\
\left(1-\tau_{y_{s i}}\right) & =\frac{\sigma}{\sigma-1} \frac{1}{\left(1-\alpha_{s}-\beta_{s}\right)} \frac{Z_{s} Q_{s i}}{P_{s i} Y_{s i}}
\end{aligned}
$$

Equation (8) allows us to estimate the three wedges from information on gross output, input costs and the elasticities $\sigma, \alpha_{s}$ and $\beta_{s}{ }^{8}$

In order to proceed, we now distinguish between total factor quantity productivity $(T F P Q)$ and total factor revenue productivity $(T F P R)$. The first tells us how many units of output a firm can obtain from using one unit of mix of factors of production, while the latter tells us how much revenue can be obtained from the same amount of factors of production. Thus, we define

$$
T F P Q_{s i}=A_{s i}=\frac{Y_{s i}}{\left(K_{s i}^{\alpha_{s}} H_{s i}^{\beta_{s}} Q_{s i}^{1-\alpha_{s}-\beta_{s}}\right)}
$$

and

$$
T F P R_{s i}=P_{s i} A_{s i}=\frac{P_{s i} Y_{s i}}{\left(K_{s i}^{\alpha_{s}} H_{s i}^{\beta_{s}} Q_{s i}^{1-\alpha_{s}-\beta_{s}}\right)}
$$

From equation (7) we get:

$$
\operatorname{TFPR}_{s i}=\frac{\sigma}{\sigma-1} \Psi_{s} \frac{\left(1+\tau_{k_{s i}}\right)^{\alpha_{s}}\left(1+\tau_{h_{s i}}\right)^{\beta_{s}}}{\left(1-\tau_{y_{s i}}\right)}
$$

Equation (11) shows that in our simple model TFPR does not vary across firms

\footnotetext{
${ }^{8}$ Note that, for instance, we infer the presence of a capital distortion in the model when the ratio of intermediate consumption to the capital costs is high relative to what one would expect from the output elasticities with respect to capital and intermediate inputs. Similarly, we deduce an output distortion when the intermediate input share is low compared to what one would expect from the industry elasticity of output with respect to intermediate inputs (and the adjustment for rents).
} 
within the same industry unless firms face some type of distortion. Intuitively, in the absence of distortions, more capital, labor and intermediate inputs would be allocated to firms with higher TFPQ to the point where their higher output results in a lower price and the exact same TFPR as in firms with lower TFPQ. In contrast, in the presence of distortions, a high (low) TFPR is a sign that the firm confronts barriers (benefits from subsidies) that raise (reduce) the firm's marginal products of the different factors of production, rendering the firm smaller (larger) than optimal.

From the demand equation (4), it is straightforward to show that real and nominal output at the firm level are given by the following functions of $T F P Q_{s i}$ and $T F P R_{s i}$ :

$$
\begin{aligned}
& Y_{s i}=\left(\frac{A_{s i}}{T F P R_{s i}}\right)^{\sigma} \\
& P_{s i} Y_{s i}=\left(\frac{A_{s i}}{T F P R_{s i}}\right)^{\sigma-1}
\end{aligned}
$$

Equations 12 and $(13)$ allow us to derive the levels of efficient real and nominal output, which we denote as $Y_{s i}^{*}$ and $\left(P_{s i} Y_{s i}\right)^{*}$, respectively. These are the levels of real and nominal output that result when the distortions are eliminated, such that total factor revenue productivities $\left(T F P R_{s i}\right)$ are equalized across firms in industry $s$. If $T F P R_{s}^{*}$ denotes the efficient level of total factor revenue productivity common to all firms in industry $s, Y_{s i}^{*}$ and $\left(P_{s i} Y_{s i}\right)^{*}$ will be given by:

$$
\begin{aligned}
& Y_{s i}^{*}=\left(\frac{A_{s i}}{T F P R_{s}^{*}}\right)^{\sigma}=Y_{s i}\left(\frac{T F P R_{s i}}{T F P R_{s}^{*}}\right)^{\sigma} \\
& \left(P_{s i} Y_{s i}\right)^{*}=\left(\frac{A_{s i}}{T F P R_{s}^{*}}\right)^{\sigma-1}=P_{s i} Y_{s i}\left(\frac{T F P R_{s i}}{T F P R_{s}^{*}}\right)^{\sigma-1}
\end{aligned}
$$


An important question is how to define $T F P R_{s}^{*}$. One possibility would be to use the industry level TFPR that is obtained when all wedges are equal to zero. However, this definition does not guarantee that in equilibrium the demand for factors of production at the industry level will be the same before and after the reallocation of resources. This would have general equilibrium effects which would lead to changes in the prices of the factors of production. An alternative definition of $T F P R_{s}^{*}$, that we will adopt here, is the one that is obtained when all firms face the same average wedges, and these are such that the demand for factors of production at the industry level is the same before and after the reallocation of resources. If $\left(1+\bar{\tau}_{k_{s}}\right),\left(1+\bar{\tau}_{h_{s}}\right)$ and $\left(1-\bar{\tau}_{y_{s}}\right)$ represent such wedges, these are given by the following expressions (see Appendix B):

$$
\begin{aligned}
\left(1+\bar{\tau}_{k_{s}}\right) & =\frac{\alpha_{s}}{\left(1-\alpha_{s}-\beta_{s}\right)} \frac{Z_{s} Q_{s}}{R_{s} K_{s}} \\
\left(1+\bar{\tau}_{h_{s}}\right) & =\frac{\beta_{s}}{\left(1-\alpha_{s}-\beta_{s}\right)} \frac{Z_{s} Q_{s}}{W_{s} H_{s}} \\
\left(1-\bar{\tau}_{y_{s}}\right) & =\frac{\sigma}{\sigma-1} \frac{1}{\left(1-\alpha_{s}-\beta_{s}\right)} \frac{Z_{s} Q_{s}}{\left(P_{s} Y_{s}\right)^{*}}
\end{aligned}
$$

where $\left(P_{s} Y_{s}\right)^{*}=\sum_{i=1}^{M_{s}}\left(P_{s i} Y_{s i}\right)^{*}$ is the industry efficient nominal output, $K_{s}=\sum_{i=1}^{M_{s}} K_{s i}$, $H_{s}=\sum_{i=1}^{M_{s}} H_{s i}$ and $Q_{s}=\sum_{i=1}^{M_{s}} Q_{s i}$ are the actual industry levels of the capital stock, labor and intermediate inputs, respectively.

We can now derive the expression for $T F P R_{s}^{*}$. Replacing the firm-specific wedges by the industry average wedges in (11) we have:

$$
T F P R_{s}^{*}=\frac{\sigma}{\sigma-1} \Psi_{s} \frac{\left(1+\bar{\tau}_{k_{s}}\right)^{\alpha_{s}}\left(1+\bar{\tau}_{h_{s}}\right)^{\beta_{s}}}{\left(1-\bar{\tau}_{y_{s}}\right)}
$$


and using (16) for industry average wedges we get:

$$
\begin{aligned}
\operatorname{TFP}_{s}^{*} & =\frac{\frac{\sigma}{\sigma-1} \Psi_{s}\left[\left(\frac{\alpha_{s}}{1-\alpha_{s}-\beta_{s}}\right) \frac{Z_{s} Q_{s}}{R_{s} K_{s}}\right]^{\alpha_{s}}\left[\left(\frac{\beta_{s}}{1-\alpha_{s}-\beta_{s}}\right) \frac{Z_{s} Q_{s}}{W_{s} H_{s}}\right]^{\beta_{s}}}{\left(\frac{\sigma}{\sigma-1}\right)\left(\frac{Z_{s} Q_{s}}{1-\alpha_{s}-\beta_{s}}\right)\left(\frac{1}{K_{s}^{\alpha_{s}} H_{s}^{\beta_{s}} Q_{s}^{1-\alpha_{s}-\beta_{s}}}\right)\left(\frac{K_{s}^{\alpha_{s}} H_{s}^{\beta_{s}} Q_{s}^{1-\alpha_{s}-\beta_{s}}}{\sum_{i=1}^{M_{s}} A_{s i}^{\sigma-1}}\right)^{\frac{1}{\sigma}}} \\
& =\left(\frac{\sum_{i=1}^{M_{s}} A_{s i}^{\sigma-1}}{K_{s}^{\alpha_{s}} H_{s}^{\beta_{s}} Q_{s}^{1-\alpha_{s}-\beta_{s}}}\right)^{\frac{1}{\sigma}}
\end{aligned}
$$

By combining the various results presented above it is straightforward to write the expression for the real gross-output gains at the industry level:

$$
\begin{aligned}
\frac{Y_{s}^{*}}{Y_{s}}= & \left.\frac{\left[\sum_{i=1}^{M_{s}}\left(Y_{s i}^{*}\right)^{\frac{\sigma-1}{\sigma}}\right]^{\frac{\sigma}{\sigma-1}}}{\left[\sum_{i=1}^{M_{s}}\left(Y_{s i}\right)^{\frac{\sigma-1}{\sigma}}\right]^{\frac{\sigma}{\sigma-1}}}=\frac{\left[\sum_{i=1}^{M_{s}}\left(\left(\frac{A_{s i}}{T F P R_{s}^{*}}\right)^{\sigma}\right)^{\frac{\sigma-1}{\sigma}}\right]^{\frac{\sigma}{\sigma-1}}}{\left[\sum_{i=1}^{M_{s}}\left(\left(\frac{A_{s i}}{T F P R_{s i}}\right)^{\sigma}\right)^{\frac{\sigma-1}{\sigma}}\right]^{\frac{\sigma}{\sigma-1}}}\right]^{\frac{\sigma}{\sigma-1}} \\
& =\left[\frac{\sum_{i=1}^{M_{s}} A_{s i}^{\sigma-1}}{\sum_{i=1}^{M_{s}}\left(A_{s i} \frac{T F P R_{s}^{*}}{T F P R_{s i}}\right)^{\sigma-1}}\right]^{\frac{\sigma}{\sigma}}
\end{aligned}
$$

Now, using the Cobb-Douglas aggregator given by equation (1) we get:

$$
\frac{Y^{*}}{Y}=\prod_{s=1}^{S}\left\{\frac{Y_{s}^{*}}{Y_{s}}\right\}^{\theta_{s}}=\prod_{s=1}^{S}\left\{\left[\frac{\sum_{i=1}^{M_{s}} A_{s i}^{\sigma-1}}{\sum_{i=1}^{M_{s}}\left(A_{s i} \frac{T F P R_{s}^{*}}{T F P R_{s i}}\right)^{\sigma-1}}\right]^{\frac{\sigma}{\sigma-1}}\right\}^{\theta_{s}}
$$

Equations 19 and 20 will be used to compute industry and economy aggregate gross output reallocation gains, respectively. As the exercise fixes the total amount of inputs and calculates how much gross output could be increased by reallocating resources between firms within each industry, it follows that potential gross-output gains coincide with potential TFP gains, so that 20) gives us the potential efficiency gains both in terms of gross output and TFP. In Appendix B, we show that the efficiency gains given by equations (19) and (20) are the same as those obtained in Hsieh and Klenow (2009), who follow a different route to obtain the expression for TFP gains $9^{9}$

\footnotetext{
${ }^{9} \mathrm{An}$ alternative derivation for the final expression of $T F P R_{s}^{*}$ is also presented in Appendix B.
} 
Equations (19) and (20) show that in order to compute gross output or TFP gains, we only need to compute $T F P R_{s i}, T F P Q_{s i}\left(\right.$ or $\left.A_{s i}\right)$ and $T F P R_{s}^{*}$. These three quantities can be computed without estimating the wedges. Once the model structure has been defined and it is assumed that the industry-level demand for factors of production does not change with reallocation, the only important decision for this calculation is the way we measure the different factors of production. Different ways of measuring factors of production will lead to different estimates of $T F P R_{s i}, T F P Q_{s i}$ and $T F P R_{s}^{*}$ which will ultimately lead to different estimates of industry-level and aggregate TFP gains. In other words, the assumptions made regarding the prices of factors or how the wedges are defined have no impact on the estimation of TFP gains.

Equations (19) and 20 allow us to compute gross output or TFP reallocation gains. However, we are also interested in knowing how the gross-output or $T F P$ gains translate into value-added gains as these will be more closely related to welfare gains. The way we do this is similar to the way GDP is computed in national accounts. For industry $s$, value-added gains are given by:

$$
\frac{V_{s}^{*}}{V_{s}}=\frac{\left(P_{s} Y_{s}\right)\left(\frac{Y_{s}^{*}}{Y_{s}}\right)-Z_{s} Q_{s}}{P_{s} Y_{s}-Z_{s} Q_{s}}=\frac{\left(\frac{Y_{s}^{*}}{Y_{s}}\right)-q_{s}}{1-q_{s}}
$$

while the whole economy aggregate value-added gains are computed as:

$$
\frac{V^{*}}{V}=\frac{(P Y)\left(\frac{Y^{*}}{Y}\right)-Z Q}{P Y-Z Q}=\frac{\left(\frac{Y^{*}}{Y}\right)-q}{1-q}
$$

where $\frac{Y_{s}^{*}}{Y_{s}}$ and $\frac{Y^{*}}{Y}$ are given by 19 and 20 and $q$ and $q_{s}$ are the total economy and the industry-level intermediate inputs shares, respectively. In our empirical section we will compute gross-output and value-added gains for different groupings of industries (agriculture vs manufacturing vs services) and for each case these formulas will be adjusted accordingly. 


\section{The data}

In this paper we use firm balance sheet data and industry level factor shares. The firm balance sheet data come from Instituto Nacional de Estatística (INE), the Portuguese Statistics Institute, and covers the period 1996 to 2011. The source of the information for the 1996-2004 subperiod is the Inquérito à Empresa Harmonizado (IEH), while for the 2004-2011 subperiod the information comes from the Sistema de Contas Integradas das Empresas (SCIE). The two sources of data provide very detailed information on the firm's balance sheet and income statement.

In order to obtain the final dataset we combined the data from IEH with the data from SCIE. These two sources are significantly different in their construction because the IEH dataset is a stratified sample while the SCIE is a census. Because the two sources have 2004 in common, we are able to estimate the strata weights which will allow us to use the IEH information as if it were a representative sample. ${ }^{10}$

An additional important difference between the two samples is that to be included in the IEH, firms must have at least 20 employees, but they will remain in the sample even if the number of employees declines. In order to mimic this restriction we exclude all firms that have less than 20 employees in the first year they are observed in the census sample.

In the final sample, from 1996 to 2011, there are a total of 209,259 observations corresponding to 36,512 different firms. From this dataset we get information on firms's gross output, value added, consumption of intermediate inputs, labor costs (wages and benefits including social security contributions), employment (average number of employees), gross investment (or gross fixed capital formation), annual and accumulated

\footnotetext{
${ }^{10}$ The estimates of strata weights that we use for the period 1996 to 2003 correspond to the ratio of the number of firms with $\mathrm{X}$ to $\mathrm{Y}$ employees in the census data compared to the number of firms in the same size range in the stratified sample. For example, we observe that in the 2004 census (SCIE) there are 4677 firms with 40 to 75 employees, while in the stratified sample for the same year (IEH) there are only 2441 firms. In this case, we use a weight of $1.91=4677 / 2441$ for all firms with 40 to 75 employees in the years 1996 to 2003.

Appendix B provides the formulas with weights corresponding to equations $(18),(19)$ and $(20)$ that are used to compute TFP or gross-output efficiency gains.
} 
depreciations and the book values of gross and net capital stock.

The dataset also includes information on the firms's main industry of operation based on the European Classification of Economic Activities (NACE). For our purposes, industries are defined at the 3-digit NACE code (Rev. 2.1). Overall, this classification implies 212 different industries (115 for manufacturing, 9 for agriculture (including mining and quarrying) and 88 for services (including production and distribution of electricity, water supply and construction)).

As discussed in the previous section, the estimates of resources misallocation are almost exclusively determined by the measures of output and factors of production that are used. In terms of outcome variables, we use both gross output and value added. These are computed directly by the INE using original data from firms' balance sheets and applying the National Accounts identities. Gross output reflects the value of production at market prices, while value added is the difference between gross output and consumption of intermediate inputs. As a measure of labor we use both the total wage bill and the number of paid employees, as alternative measures.

An important issue regards the measure of the capital stock. As Oberfield (2013) notes, the most prominent measurement issue is that capital is notoriously difficult to measure and the extent of misallocation may be overstated if capital is poorly measured. Some papers use energy consumption under the assumption that capital services require fixed proportions of energy and capital (see, for instance, Oberfield (2013) and Sandleris and Wright (2011)). Here, we follow the most common approach (Hsieh and Klenow (2009), Ziebarth (2013), Machicado and Birbuet (2012), Chen and Irarrazabal (2013), among others) and use the book value of the total capital stock net of depreciations (tangible and intangible assets) taken from firms' balance sheets. ${ }^{11}$

For the industry-level factor shares, we use the average factor shares that are ob-

\footnotetext{
${ }^{11}$ We note that capital book values taken from firms' balance sheets include different generations of capital (past investments) valued at different (historical) prices, so some comparability issues across firms may be expected. However, this will not be a problem if the structure of the capital stock (proportion of different types of capital) is the same for all the firms in the industry, implying a common capital deflator.
} 
served in the US during the period 1998 to 2010, which are published by the Bureau of Economic Analysis (BEA) ${ }^{12}$ An important remark to be made is that the data on worker compensation includes both the salaries as well as other labor costs such as pension contributions or fringe benefits ${ }^{13}$ Further, because industry classification is different in the two countries we make an approximate concordance between the two classifications 14

\section{Empirical results}

In this section, we present our main results regarding the gross-output and value-added reallocation gains resulting from an hypothetical exercise where distortions are removed so that TFPR levels are equalized across firms in each industry.

In our baseline computations we present the results for gross-output and valueadded reallocation gains using the sample for the period 1996-2011, which excludes firms entering with less than 20 employees. Later, given the importance of small firms in the Portuguese economy, we also compute the reallocation gains for the 2004-2011 period, using the full census of firms operating in Portugal. For comparability reasons, in Appendix A we present the results obtained when a two-factor value-added function is considered as in Hsieh and Klenow (2009).

A central parameter in this methodology is $\sigma$, the elasticity of substitution between firms' gross output. In line with other studies, we set $\sigma=3$ in our baseline computations. The value of this parameter has important consequences for the magnitude of the results. Therefore, we will conduct some sensitivity tests with alternative values of

\footnotetext{
${ }^{12}$ In our model, it is not possible to separately identify the average input distortions (average wedges) and the input elasticities in each industry. Thus, using factor shares from the U.S. economy is a simple way to control for distortions that could affect the input shares in the Portuguese economy, while the U.S. is taken as a benchmark of a relatively undistorted economy.

${ }^{13}$ Note that these data are different from what is available on the factor shares dataset from the NBER that was used, for instance, in Hsieh and Klenow (2009) and Ziebarth (2013) in that the latter do not include the other labor costs such as pension contributions and fringe benefits.

${ }^{14}$ In the small number of cases for which we were not able to find a good match, we used the average for the whole economy in the U.S.. Between 1998 and 2010, gross output was composed of 46 percent consumption of intermediate inputs, 33 percent labor compensation and the remaining 21 percent were the compensation to capital owners.
} 
$\sigma$

In line with other studies, we use the wage bill paid by the firm (total labor costs) to measure labor input in our baseline calculations. Implicitly, we are assuming that wages per worker adjust for firm differences in hours worked per worker and worker skills. This means that in our model $H_{s i}=w_{s i} L_{s i}$ and $W_{s}=1$, where $L_{s i}$ stands for employment and $w_{s i}$ for the firm specific average wage rate. We will also investigate the consequences of measuring the labor input by the number of employees.

For the rental price of capital, we define an industry specific price equal to the industry depreciation rate plus a 5 percent real interest rate, so that $R_{s}=\delta_{s}+0.05{ }^{15}$ For the intermediate inputs, we make a similar assumption as in the case of the labor input, and assume that the price of intermediate products, $Z_{s}$, is equal to 1 , so that the expenditure on intermediate inputs reflects not only the amount of inputs but also their quality.

In the data we observe nominal output $\left(P_{s i} Y_{s i}\right)$, but not firm-specific output prices, so to calculate the firm's real gross output we use the relationship between nominal and real output that is assumed by the model. From (4), and using the assumption $Y_{s}^{\frac{1}{\sigma}} P_{s}=1$, we get

$$
Y_{s i}=\left(P_{s i} Y_{s i}\right)^{\frac{\sigma}{\sigma-1}}
$$

We use equation (23) to compute the firm's real gross output. That is, we infer price versus quantity from nominal gross output and an assumed elasticity of demand. From the estimates of real output we can obtain estimates of firm-level total factor productivity $\left(T F P Q_{s i}=A_{s i}\right)$.

Finally, before computing the gains from our hypothetical reallocation exercise, we trim the 1 percent tails of $\log \left(T F P R_{s i} / T F P R_{s}^{*}\right)$ and $\log \left(A_{s i} M_{s}^{\frac{1}{\sigma-1}} / T F P_{s}^{*}\right)$ across

\footnotetext{
${ }^{15}$ Note that the value for $R_{s}$ only affects the average capital distortion but not the relative comparison between firms in a given industry. In other words, the choice of $R_{s}$ affects the estimates of the capital wedge, but not the efficiency gains calculated in this paper.
} 


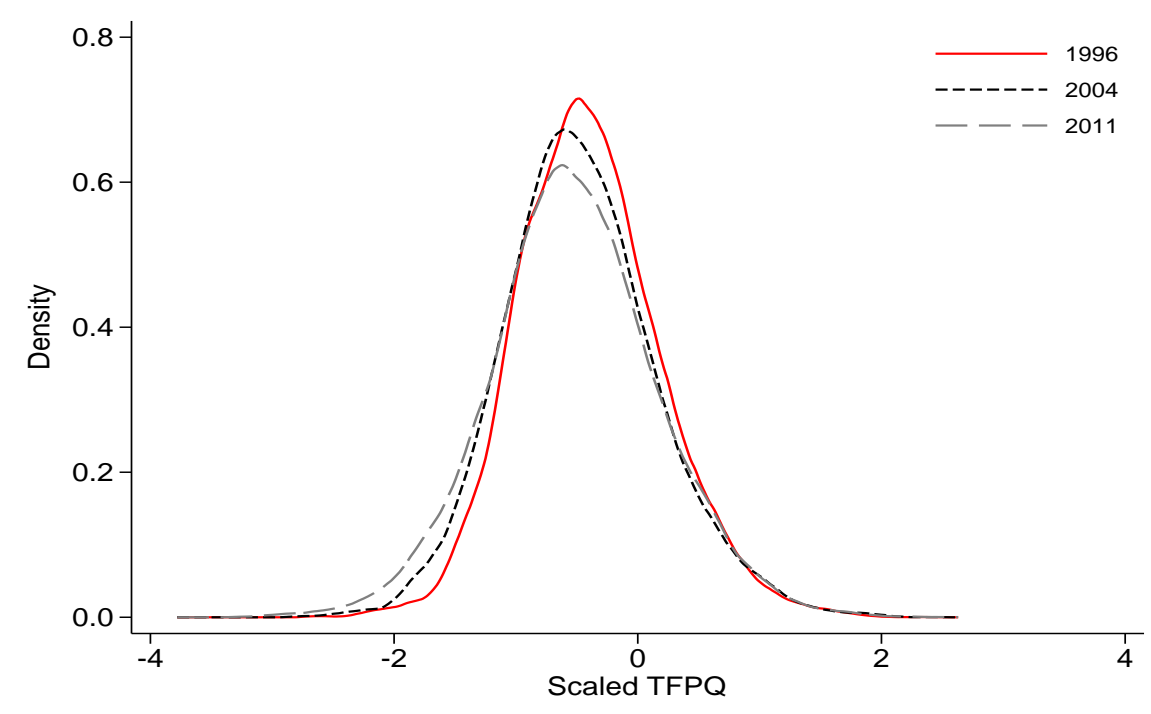

Figure 2: Density of TFPQ

industries ${ }^{16}$ That is, we pool all industries and omit the top and bottom 1 percent of firms in each of the pools to eliminate outliers and to control for possible measurement error. We then recalculate the relevant industry level aggregates such as $L_{s}, K_{s}, Q_{s}$, $P_{s} Y_{s}, T F P R_{s}^{*}, T F P_{s}^{*}$, and $\theta_{s}=P_{s} Y_{s} / Y$

\subsection{Productivity dispersion}

In order to understand TFP levels and growth during the lead up to the Eurozone crisis, it is important to analyse the distribution of the physical productivity measure (TFPQ) and revenue productivity measure (TFPR). To characterize the dynamics of the distributions we choose three years of the sample: 1996, 2004 and 2011. Figure 2 plots the distribution of scaled TFPQ, i.e., $\log \left(A_{s i} M_{s}^{\frac{1}{\sigma-1}} / T F P_{s}^{*}\right)$, for our baseline model.

In Figure 2, the left tail gets thicker over time suggesting the presence of policies favouring the survival of inefficient firms (firms with relatively low TFPQ). Table 1 (which also reports the results for the manufacturing and service sectors) shows that

\footnotetext{
${ }^{16} T F P_{s}^{*}$ is defined as the industry level efficient TFP and is given by $T F P_{s}^{*}=\left(\sum_{i=1}^{M_{s}} A_{s i}^{\sigma-1}\right)$. See Appendix B for details.
} 
this pattern, with respect to the total economy, is consistent across several measures of dispersion of scaled TFPQ: the standard deviation (S.D.), the 75th minus the 25th percentiles, and the 90th minus the 10th percentiles. The standard deviation increased from 0.59 in 1996 to 0.69 in 2011, and the difference of the 90th minus the 10th percentiles increased from 1.46 to 1.74. Similar conclusions apply for the difference of the 75 th minus the 25 th percentiles.

Table 1: Dispersion of TFPQ

\begin{tabular}{|l|c|c|c|c|c|c|c|c|c|}
\hline \hline & \multicolumn{3}{|c|}{1996} & \multicolumn{3}{c|}{2004} & \multicolumn{3}{c|}{2011} \\
\cline { 2 - 10 } & Total & Manuf. & Serv. & Total & Manuf. & Serv. & Total & Manuf. & Serv. \\
\hline \hline S.D. & 0.59 & 0.56 & 0.62 & 0.63 & 0.57 & 0.67 & 0.69 & 0.60 & 0.73 \\
$75-25$ & 0.77 & 0.74 & 0.80 & 0.80 & 0.74 & 0.87 & 0.87 & 0.77 & 0.94 \\
$90-10$ & 1.46 & 1.41 & 1.52 & 1.58 & 1.41 & 1.68 & 1.74 & 1.48 & 1.83 \\
\hline \hline
\end{tabular}

Note: Statistics are for $\log \left(A_{s i} M_{s}^{\frac{1}{\sigma-1}} / T F P_{s}^{*}\right)$. S.D.=Standard deviation, $75-25$ is the difference between the 75 th and 25 th percentiles, and the $90-10$ the 90 th vs. 10th percentiles.

By looking at the manufacturing and service sectors, we conclude that the increase in dispersion for the whole economy stems mainly from the service sector. The standard deviation of scaled TFPQ for the manufacturing sector increases slightly, from 0.56 in 1996 to 0.60 in 2011 (7.1 percent), while it shows a strong increase in the service sector from 0.62 to 0.73 (17.7 percent). Similarly, the difference of the 90th minus the 10th percentiles increased from 1.41 to 1.48 (5.0 percent) in manufacturing and from 1.52 to 1.83 (19.7 percent) in the service sector ${ }^{17}$

Figure 3 plots the distribution of scaled TFPR, i.e., $\log \left(T F P R_{s i} / T F P R_{s}^{*}\right)$ for 1996 , 2004 and 2011, and Table 2 provides scaled TFPR dispersion statistics for the total economy, as well as for the manufacturing and service sector. In an efficient allocation, marginal returns are equated across firms and therefore the dispersion of marginal returns and thus of TFPR would be zero. Therefore, higher dispersion suggests more misallocation of resources across firms, as a result of distortions that affect firms differently in each industry. In other words, high levels of TFPR dispersion highlight poten-

\footnotetext{
${ }^{17}$ For agriculture, which is of little importance in our sample, the corresponding figures are 0.51 and 0.63 (standard deviation), and 1.20 and 1.55 (the 90th minus the 10th percentiles) for 1996 and 2011, respectively (figures not shown in Table 1 ).
} 


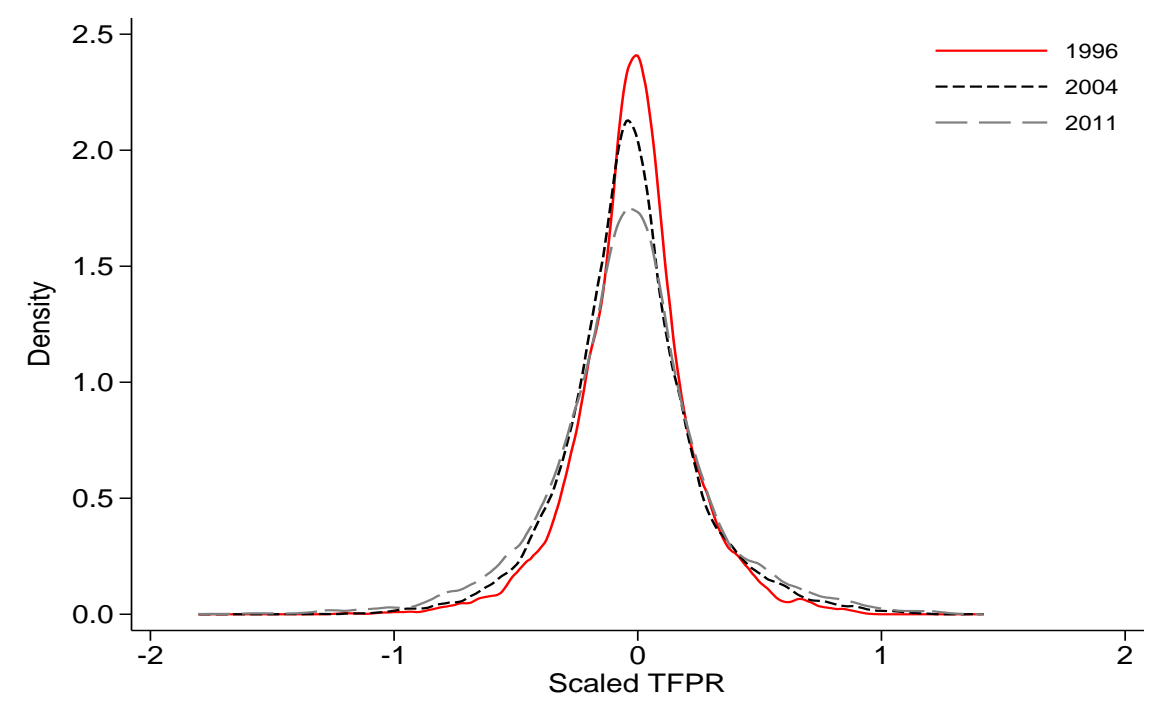

Figure 3: Density of TFPR

tial gains in productivity that could be achieved by reallocating factors of production from firms with lower marginal revenues to those with higher marginal revenues. From Figure 3 and Table 2, we conclude that the dispersion of scaled TFPR increased over time. Irrespective of the dispersion measure we look at, there is clearly more TFPR dispersion in 2011 than in 1996 and 2004 18 Also, dispersion measures are higher in the service sector than in the manufacturing sector, suggesting that efficiency gains may be larger in the former.

Table 2: Dispersion of TFPR

\begin{tabular}{|l|c|c|c|c|c|c|c|c|c|}
\hline \hline & \multicolumn{3}{|c|}{1996} & \multicolumn{3}{c|}{2004} & \multicolumn{3}{c|}{2011} \\
\cline { 2 - 10 } & Total & Manuf. & Serv. & Total & Manuf. & Serv. & Total & Manuf. & Serv. \\
\hline \hline S.D. & 0.23 & 0.19 & 0.27 & 0.27 & 0.22 & 0.29 & 0.32 & 0.25 & 0.35 \\
$75-25$ & 0.24 & 0.18 & 0.31 & 0.27 & 0.20 & 0.34 & 0.32 & 0.22 & 0.39 \\
$90-10$ & 0.53 & 0.42 & 0.65 & 0.62 & 0.47 & 0.70 & 0.72 & 0.52 & 0.82 \\
\hline \hline
\end{tabular}

Note: Statistics are for $\log \left(T F P R_{s i} / T F P R_{s}^{*}\right)$. S.D.=Standard deviation, $75-25$ is the difference between the 75 th and 25 th percentiles, and the $90-10$ the 90 th vs. 10 th percentiles.

\footnotetext{
${ }^{18}$ We note that the dispersion measures of scaled TFPR and scaled TFPQ for 1996 are computed using weights (see Section 3 above). The presence of weights may reduce the estimates for those dispersion measures (there would be more firms with the same TFPR and the same TFPQ, than otherwise), and thus distort their time profile when comparing the first subperiod (1996-2003) with the second subperiod (2004-2011). However, the fact that the measures of dispersion also increase over the 1996-2003 subperiod (where weights are constant) suggests that the idea of increasing misallocation over the 1996-2011 period is not an artifact stemming from the presence of weights.
} 
Table 3: Correlation between TFPR and TFPQ

\begin{tabular}{|l|c|c|c|c|}
\hline \hline & $\begin{array}{c}\text { Average } \\
(1996-2011)\end{array}$ & 1996 & 2004 & 2011 \\
\hline \hline Total & 0.50 & 0.41 & 0.49 & 0.55 \\
Manufacturing & 0.27 & 0.23 & 0.26 & 0.32 \\
Services & 0.58 & 0.55 & 0.59 & 0.62 \\
\hline \hline
\end{tabular}

Note: Entries are the correlations between $\log \left(A_{s i} M_{s}^{\frac{1}{\sigma-1}} / T F P_{s}^{*}\right)$ and $\log \left(T F P R_{s i} / T F P R_{s}^{*}\right)$. All the estimates are significant at 1 percent level.

To further investigate potential resource misallocation among firms of different TFPR, we compute the correlation between TFPQ and TFPR. Restuccia and Rogerson (2008) emphasize this correlation as particularly harmful for aggregate productivity since when the correlation is positive, the most physically productive firms also face the highest implicit distortions. In contrast, if dispersion in TFPR across firms is not correlated with TFPQ, TFPR dispersion may not lead to large productivity losses, and thus efficiency gains may be small. Table 3 shows that TFPQ and TFPR are positively correlated, which means that more productive firms tend to face higher distortions and thus tend to produce less, while less productive firms tend to overproduce. Moreover, the correlation has increased over time and is larger in the service sector, suggesting that we may expect larger and increasing efficiency gains in this sector.

\subsection{Reallocation gains}

Table 4 provides gross-output gains from fully equalizing TFPR across firms in each industry for our baseline model. We provide figures for 5 years of our sample (1996, 1999, 2004, 2008 and 2011), featuring aggregate and sectoral information for the grossoutput and value-added gains computed from equations (19)-(22).

Two important results emerge from Table 4. First, the potential gains from eliminating distortions in the Portuguese economy appear to be modest in terms of gross output, but are quite significant when evaluated in terms of value added. For instance, if we look at the gross-output gains for the whole economy, we conclude that in 2011 
actual output would increase by around 28 percent if the identified distortions were eliminated from the economy. However, these gross-output gains would imply valueadded gains of around 79 percent. The difference stems from the fact that gross-output gains at the industry level are computed under the assumption of constant intermediate inputs, so that, according to equation (21), even small gains in terms of gross output may imply very large value-added gains. This will especially be the case in the industries where intermediate inputs are a large proportion of gross output.

As expected from Table 2 s results, the largest gains in terms of gross output occur in the service sector (around 38 percent in 2011), while the manufacturing sector displays more modest gains (around 14 percent). However, these gross-output gains translate into significant value-added gains especially in the service sector (92 percent in 2011).

Table 4: Output gains from equalizing TFPR within industries

\begin{tabular}{|c|c|c|r|c|}
\hline \hline Years & Total Economy & Agriculture & Manufacturing & Services \\
\hline \hline \multicolumn{5}{|c|}{ Gross-output gains } \\
\hline \hline 1996 & 16.91 & 24.84 & 11.21 & 24.42 \\
1999 & 17.41 & 17.78 & 10.70 & 24.95 \\
2004 & 23.69 & 19.26 & 12.37 & 32.27 \\
2008 & 28.86 & 17.02 & 13.24 & 39.26 \\
2011 & 28.03 & 31.29 & 13.66 & 38.44 \\
\hline \hline \multicolumn{5}{|c|}{ Value-added gains } \\
\hline \hline 1996 & 48.00 & 57.11 & 37.49 & 58.17 \\
1999 & 48.15 & 38.62 & 35.34 & 58.63 \\
2004 & 63.25 & 45.47 & 40.49 & 76.49 \\
2008 & 78.94 & 40.61 & 47.86 & 93.93 \\
2011 & 79.01 & 81.82 & 53.53 & 91.51 \\
\hline \hline
\end{tabular}

Note: Entries for gross-output gains are given by $\left(Y_{s}^{*} / Y_{s}-1\right)^{*} 100$ and $\left(Y^{*} / \mathrm{Y}-1\right)^{*} 100$ where $Y_{s}^{*} / Y_{s}$ and $Y^{*} / Y$ are computed from equations 19 and 20 , respectively. Entries for value-added gains are given by $\left(V_{s}^{*} / V_{s}-1\right)^{*} 100$ and $\left(V^{*} / \mathrm{V}-1\right)^{*} 100$ were $V_{s}^{*} / V_{s}$ and $V^{*} / \mathrm{V}$ are computed from equations 21) and 22, respectively. The labor input is measured by the wage bill $\left(H_{s i}=W_{s i} L_{s i}\right)$ and the intermediate input by $Q_{s i}=Z_{s} Q_{s i}$ with $Z_{s}=1$.

Duarte and Restuccia (2007, 2010) suggest that the lower degree of competition in the service sector in relation to manufacturing is one potential reason why across countries there was more convergence to the world frontier in manufacturing than 
in services (and agriculture). Services are, in general, nontradables and often heavily protected by regulations. Moreover, variables like location play a much more important role in services than in manufacturing. Extensive misallocation is a symptom of a lack of competition for resources, as policies, market failures, or location advantages favour some firms relative to others for reasons other than their relative efficiency.

A second important point to note from Table 4 and Figure 4 is that efficiency gains for the whole economy increased significantly over time. This is a reflection of increasing misallocation over the sample period, as the evidence on scaled TFPR dispersion in the previous subsection would suggest.

Between 1996 and 2011 the hypothetical efficient levels of gross output increased from 17 percent to 28 percent above actual gross output levels, while efficient levels of value added increased from 48 percent to 79 percent above actual GDP levels, respectively. Thus, the decline in allocative efficiency during the sample period implied cumulative losses of 9.5 percent of gross output (1.28/1.17-1) and 21 percent of GDP. Correspondingly, deteriorating allocative efficiency in the Portuguese economy may have shaved, on average, $0.6 \mathrm{pp}$ off annual gross output growth or $1.3 \mathrm{pp}$ off annual GDP growth in the 1996-2011 period. These are very large numbers because during the same time period, Portuguese real GDP increased only 25.2 percent (1.5 percent per year, on average) 19

Table 4 and Figure 4 also show that the service sector is the main driver of this result. In fact, not only has the importance of reallocation gains increased faster in this sector than in manufacturing or agriculture, underscoring the idea of increasing misallocation of resources in services, but also the importance of services in the economy has increased significantly during this period ${ }^{20}$

\footnotetext{
${ }^{19}$ Note that the hypothetical efficiency gains estimated in this paper assume a fixed aggregate capital stock. In practice, however, it may be argued that gross output and GDP gains are likely to be amplified if, as it is usually assumed in conventional economic growth models, one allows increases in gross output or value added to translate into higher investment and thus into higher capital stock. See Hsieh and Klenow (2009) and Jones (2013) for a discussion.

${ }^{20}$ The bulk of the empirical evidence on misallocation available in the literature has been obtained using a two-factor model on value added. Thus, for comparability reasons, Appendix A discusses the results when the two-factor model, as developed in Hsieh and Klenow (2009), is used. From Table
} 


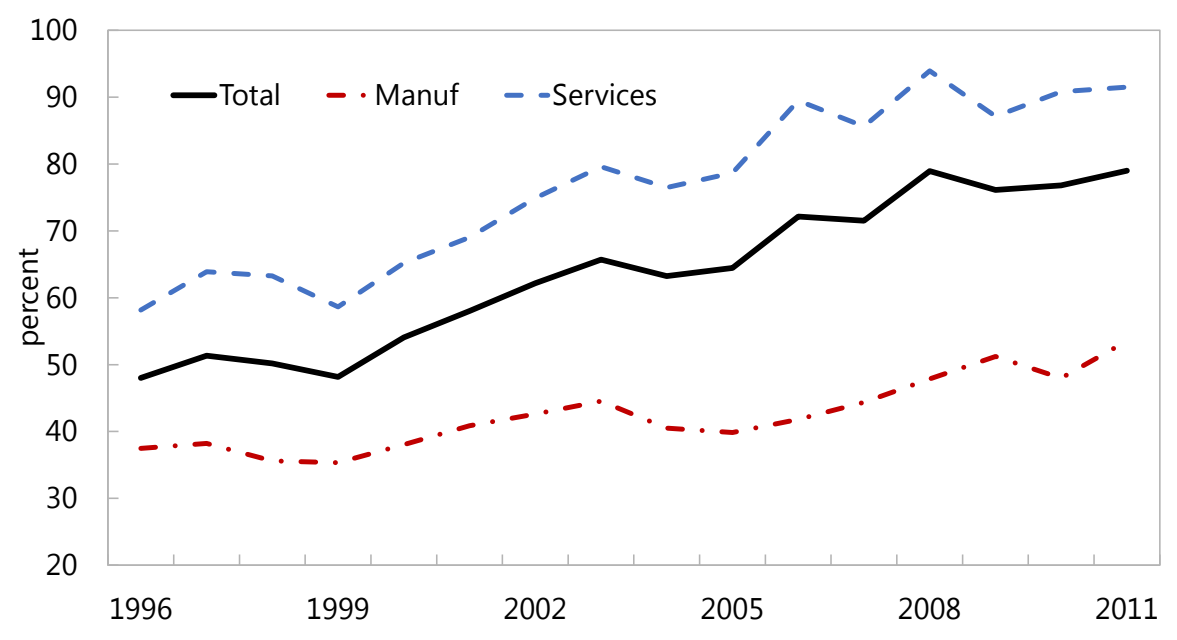

Figure 4: Value-added reallocation gains (baseline)

In order to further understand the origins of the increasing misallocation, we compute the contribution of each industry for the total variation of efficiency gains (in terms of gross output). We conclude that the top five most important industries account for 72 percent of the total variation of misallocation. Construction is the most important industry followed by ground transportation, transportation support services (e.g., road and toll-road management and maintenance), general support services (accounting, law, market research, etc.) and wholesale of food and drinks.

The top 5 most important industries on the positive side account for -17 percent of the total variation. That is, if these 5 industries had not improved their contribution to overall misallocation, the total variation of misallocation would have been 17 percent higher. The most important industry is the production and distribution of electricity, followed by rental cars, advertising (mostly due to a large reduction in the weight of A2, we conclude that value-added reallocation gains are lower than the ones presented in Table 4 . As discussed in Appendix A, the lower level of misallocation identified by the two-factor model is likely to stem from the fact that it does not allow for misallocation in intermediate inputs. Importantly, misallocation still emerges as increasing over time and the service sector still appears as the main responsible for the deterioration of allocative efficiency. According to Table A2, misallocation may have trimmed around $0.8 \mathrm{pp}$ off annual GDP growth from 1996 to 2011 . This figure is not as impressive as the one presented above, but it still represents about 50 percent of the annual GDP growth recorded during the sample period. 
production), production of alcoholic and non-alcoholic drinks, and wholesale of raw materials.

\section{Robustness checks}

This section provides three robustness checks to our baseline computations presented in Table 4. Specifically, we vary the elasticity of substitution, $\sigma$, use employment as an alternative measure for the labor input and consider the implications of accounting for firms with less than 20 employees.

\section{Elasticity of substitution}

An important issue relates to the reasonability of the assumed values for $\sigma$. In our baseline computations we set the elasticity of substitution between firms' gross output to $\sigma=3$ as this is the value most commonly used in similar empirical applications. However, there are now industry-level estimates of $\sigma$ available for several countries, so it is interesting to see how reallocation gains vary with alternative assumptions for the elasticity of substitution. Table 5 presents average estimates of $\sigma$ for the Eurozone, the US and Portugal ${ }^{21}$ We note that for the three economies the estimates of $\sigma$ are well above 3. The available estimates also show that $\sigma$ 's are higher in the manufacturing sector than in the service sector.

To see whether accounting for heterogeneity in the elasticities of substitution has important consequences for the aggregate reallocation gains, we estimate the reallocation gains for Portugal using the industry-level estimates for the elasticity of substitution taken from Christopoulou and Vermeulen (2012) and Amador and Soares (2013) (2-digit NACE codes for the US and Eurozone, and 3-digit NACE codes for Portugal,

\footnotetext{
${ }^{21}$ Figures in Table 5 are computed using the industry-level markup estimates presented in Christopoulou and Vermeulen (2012) for the US and the Eurozone, and in Amador and Soares (2013) for Portugal. We convert the industry-level markup estimates into elasticities of substitution and aggregate using Portuguese gross-output average weights for the period 1996-2011. For agriculture, as well as for a small number of industries for which markup estimates are not available in Christopoulou and Vermeulen (2012) or Amador and Soares (2013), $\sigma=3$ is used.
} 
Table 5: Estimates for the elasticity of substitution

\begin{tabular}{|l|c|c|c|}
\hline \hline & Total Economy & Manufacturing & Services \\
\hline \hline Eurozone & 5.4 & 7.4 & 4.1 \\
US & 5.6 & 7.0 & 4.7 \\
Portugal & 6.8 & 7.6 & 6.4 \\
\hline \hline
\end{tabular}

Sources: Eurozone and US (1981-2004) - Christopoulou and Vermeulen (2012); Portugal (20052009) - Amador and Soares (2013). Eurozone includes Germany, France, Italy, Spain, Netherlands, Belgium, Austria and Finland.

respectively). When the US and Eurozone industry-level estimates for $\sigma$ are used, the reallocation gains are very similar, but somewhat smaller than the ones obtained when the estimates for Portugal are used. In all three cases, however, reallocation gains increase both in terms of gross output and value added. For instance, when the US estimates for $\sigma$ are used, gross-output reallocation gains for 2011 become 43 percent (28 percent in the baseline) while the estimated value-added gains are now 123 percent (79 percent in the baseline). These figures compare with 48 percent and 142 percent, respectively, when the estimated $\sigma$ 's for Portugal are used. The service sector still emerges as the main driver of these results: in 2011, efficiency gains in the service sector are almost twice as large as those in the manufacturing sector.

Importantly, the idea of increasing misallocation overtime becomes even stronger compared to the baseline. When we use the US estimates of $\sigma$, deteriorating allocative efficiency appears as having shaved 1.0 pp off annual gross output growth or $2.0 \mathrm{pp}$ off annual GDP growth in the 1996-2011 period (1.1 pp and $2.2 \mathrm{pp}$, respectively if we use the Portuguese data). These estimates clearly suggest that figures in Table 4 , computed with $\sigma=3$, are to be seen as conservative estimates not only for the efficiency gains but also for the negative consequences of deteriorating allocative efficiency on Portuguese productivity and GDP growth.

\section{Number of employees as a measure of employment}

Our baseline model measures firm labor input using the wage bill. The assumption is that wages per worker adjust for firm differences in hours worked per worker and 
workers skills. However, one can argue that differences in wages may reflect rent sharing between firms and their workers. If this is the case, our baseline model is likely to understate differences in TFPR across firms because the most profitable firms are expected to pay higher wages. Therefore, we recalculate the gains from equalizing TFPR within industries using employment as the measure of firms' labor input. The results are presented in Table 6 and Figure 5 .

Table 6: Output gains from equalizing TFPR within industries (Labor input measured by employment)

\begin{tabular}{|c|c|c|r|r|}
\hline \hline Years & Economy & Agriculture & Manufacturing & Services \\
\hline \hline \multicolumn{5}{|c|}{ Gross-output gains } \\
\hline \hline 1996 & 21.04 & 32.67 & 13.42 & 31.41 \\
1999 & 22.78 & 21.09 & 13.43 & 33.44 \\
2004 & 29.92 & 20.75 & 15.36 & 41.38 \\
2008 & 35.41 & 19.52 & 16.22 & 48.58 \\
2011 & 35.31 & 33.30 & 15.89 & 49.82 \\
\hline \hline \multicolumn{5}{|c|}{ Value-added gains } \\
\hline \hline 1996 & 60.14 & 75.06 & 44.91 & 75.43 \\
1999 & 62.71 & 45.81 & 44.55 & 77.83 \\
2004 & 80.35 & 47.97 & 50.45 & 98.65 \\
2008 & 96.88 & 46.57 & 58.94 & 115.89 \\
2011 & 99.54 & 86.74 & 62.28 & 118.65 \\
\hline \hline
\end{tabular}

Note: Entries for gross-output gains are given by $\left(Y_{s}^{*} / Y_{s}-1\right) * 100$ and $\left(Y^{*} / \mathrm{Y}-1\right) * 100$ where $Y_{s}^{*} / Y_{s}$ and $Y^{*} / Y$ are computed from equations 19$)$ and 20 , respectively. Entries for value-added gains are given by $\left(V_{s}^{*} / V_{s}-1\right)^{*} 100$ and $\left(V^{*} / \mathrm{V}-1\right)^{*} 100$ were $V_{s}^{*} / V_{s}$ and $V^{*} / \mathrm{V}$ are computed from equations 21 and $\sqrt{22}$, respectively. The labor input is measured by the number of employees $\left(\sum H_{s i}=\sum L_{s i}\right)$ and the intermediate input by $Q_{s i}=Z_{s} Q_{s i}$ with $Z_{s}=1$.

As could be expected, the reallocation gains are larger when we measure labor input using employment. For instance, the value-added reallocation gains for the whole economy in 2011 are now 100 percent (79 percent in the baseline model). This means that Portuguese GDP would be twice as large as current GDP in 2011 if distortions were removed from the economy. If we look at the sectoral disaggregation, we see that the value-added reallocation gains in the service sector for 2011 are now around 119 percent (92 percent in the baseline). These results show that wage differences amplify TFPR differences, leading to larger efficiency gains. 


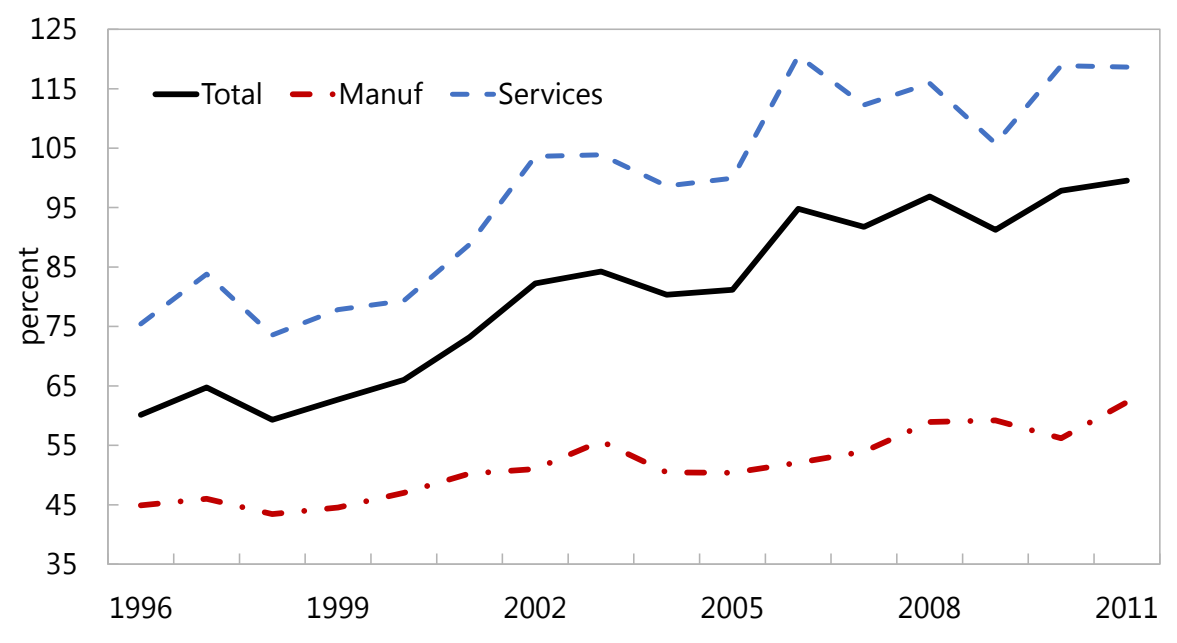

Figure 5: Value-added reallocation gains

(Labor input measured by employment)

Mainly due to the service sector, efficiency gains emerge, once again, as increasing over time with significant consequences for potential gross-output and GDP growth (see Figure 5). Based on Table 6, the decline in allocative efficiency may have shaved, on average, $0.75 \mathrm{pp}$ off annual gross output growth or $1.5 \mathrm{pp}$ off annual GDP growth in the 1996-2011 period.

\section{Census of firms}

Our baseline computations presented in Table 4 exclude entering firms with less than 20 employees, for reasons explained in Section 3. Since these firms play an important role in the Portuguese economy ${ }^{22}$ we recompute the reallocation gains using the census of firms for the 2004-2011 period. The new results are recorded in Table 7. A first important point to note is that reallocation gains are significantly higher than those recorded in Table 4 for the baseline model. For instance, the gross-output reallocation

\footnotetext{
${ }^{22}$ On average, firms with less than 20 employees contributed around 30 percent to total gross output and 40 percent to total employment over the 2004-2011 period. In the sample used in the baseline calculations for 1996-2011, that excludes such firms, the service sector represents, on average, around 69 percent of value added in the 2004-2011 period, the manufacturing sector around 30 percent and agriculture somewhat less than 1 percent. In the census data, the importance of the service sector increases to 81.4 percent, on average, while the importance of the manufacturing sector is reduced to 18.2 percent.
} 
gains for the whole economy in 2011 are now 62 percent (28 percent in the baseline model), while the corresponding value-added gains are 158 percent (79 percent in the baseline). From Table 7, we see that the increase in the output gains is mostly explained by the service sector, where value-added gains for 2011 are now 183 percent (around 92 percent in the baseline). Reallocation gains in the manufacturing sector also increase but not by as much relative to the baseline.

Table 7: Output gains from equalizing TFPR within industries (Census of firms)

\begin{tabular}{|c|c|c|c|c|}
\hline \hline Years & Total Economy & Agriculture & Manufacturing & Services \\
\hline \hline \multicolumn{5}{|c|}{ Gross-output gains } \\
\hline \hline 2004 & 49.60 & 21.33 & 17.74 & 61.88 \\
2006 & 57.20 & 27.85 & 18.11 & 71.13 \\
2008 & 61.66 & 33.61 & 20.03 & 74.36 \\
2010 & 62.10 & 30.79 & 19.23 & 74.92 \\
2011 & 62.34 & 35.07 & 20.13 & 76.00 \\
\hline \hline \multicolumn{5}{|c|}{ Value-added gains } \\
\hline \hline 2004 & 128.97 & 47.65 & 50.58 & 156.71 \\
2006 & 149.94 & 61.92 & 53.92 & 180.39 \\
2008 & 155.36 & 75.16 & 59.20 & 180.81 \\
2010 & 152.70 & 68.78 & 55.67 & 177.77 \\
2011 & 157.62 & 83.40 & 62.35 & 183.29 \\
\hline \hline
\end{tabular}

Note: Entries for gross-output gains are given by $\left(Y_{s}^{*} / Y_{s}-1\right)^{*} 100$ and $\left(Y^{*} / \mathrm{Y}-1\right)^{*} 100$ where $Y_{s}^{*} / Y_{s}$ and $Y^{*} / \mathrm{Y}$ are computed from equations 190 and 20 , respectively. Entries for value-added gains are given by $\left(V_{s}^{*} / V_{s}-1\right)^{*} 100$ and $\left(V^{*} / \mathrm{V}-1\right)^{*} 100$ were $V_{s}^{*} / V_{s}$ and $V^{*} / \mathrm{V}$ are computed from equations 21] and 22], respectively.. The labor input is measured by the wage bill $\left(H_{s i}=W_{s i} L_{s i}\right)$ and the intermediate input by $Q_{s i}=Z_{s} Q_{s i}$ with $Z_{s}=1$.

A second important point is that increasing misallocation over the 1996-2011 period still remains when we look at the census of firms for the 2004-2011 period. According to Table 7, if the importance of misallocation had remained stable at the level estimated for 2004, GDP would be 12.5 percent above its actual level in 2011. Therefore, deteriorating allocative efficiency may have shaved 1.7 pp off GDP growth during a period in which the Portuguese economy stagnated ${ }^{23}$

\footnotetext{
${ }^{23}$ Between 2004 and 2011 Portuguese GDP increased only 1.96 percent (0.28 percent per year, on average).
} 
The results above suggest that an important part of the misallocation problems due to distortions in the Portuguese economy is concentrated in the micro and small service sector firms. Note, however, that reallocation gains in some of these firms may be somewhat overestimated, because our approach does not allow for indivisibilities in the labor force, which mainly affect micro and small firms. In turn, some of these units (young firms) might be growing as they are in the process of converging to their optimal size, while others (older firms) might be shrinking as they are approaching the end of their life-cycle. Finally, because enforcement activity of tax collection focuses more on large firms, micro and small firms are more likely to exhibit noncompliance with taxes by misreporting some relevant items like sales or gross output, also implying higher distortions.

Overall, the evidence from Table 7 suggests that within-industry resource misallocation is a major problem in the service sector, but to a much lesser extent in the manufacturing sector and that such misallocation has increased over time implying significant productivity and value-added losses.

\section{Sources of misallocation and relative importance of distortions}

We now discuss the type of distortions that are likely to underly the resource misallocation documented above and investigate how the relative importance of such distortions evolved over time.

\section{Sources of misallocation}

There are reasons to believe that the relative importance of distortions may vary with the size of the firms. For instance, if distortions are due to firm-size contingent policies that favour smaller firms by reducing the cost of capital (through special lines of credit) or the cost of labor (through especial labor regulations), then returns to 

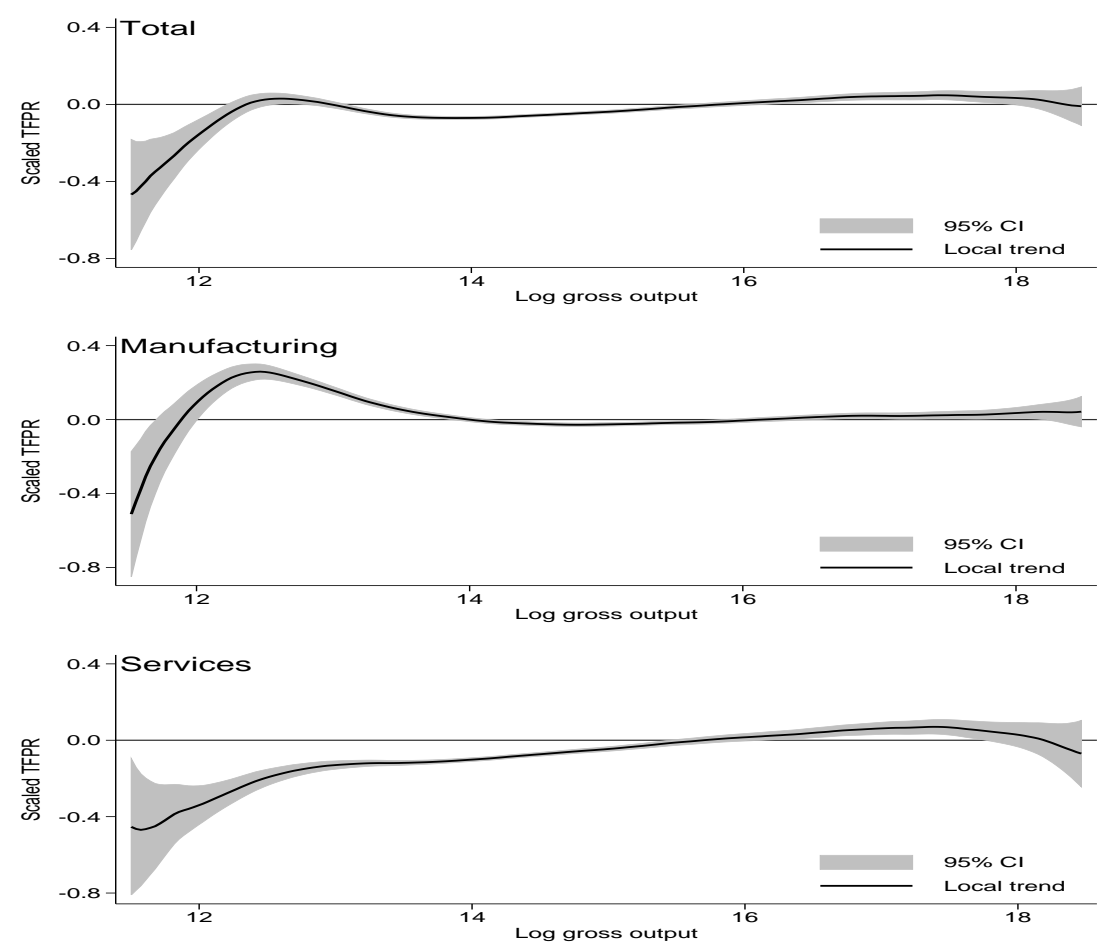

Figure 6: TFPR and firm size - 2011

additional capital and labor would be expected to be lower in smaller firms. In contrast, if misallocation is due to financial market failures that favour larger firms, we would expect the presence of many small firms that did not grow because they could not secure access to credit. Enforcement activity of tax collection may focus more on large and more productive firms implying a subsidy to small potentially less productive ones. Therefore, in order to identify the sources of distortions we start by investigating the relationship between misallocation and firm size.

Figure 6 shows the relationship between firms' size in terms of gross output and their scaled TFPR, i.e., $\log \left(T F P R_{s i} / T F P R_{s}^{*}\right)$, for the total economy, as well as for the manufacturing and service sectors in 2011 ${ }^{24}$ In an efficient allocation of resources, firms with negative scaled TFPR would decrease production (gross output) while firms with positive scaled TFPR would increase production. When the relationship between

\footnotetext{
${ }^{24}$ Data for 1996 and 2004 deliver similar qualitative results for Figures 6, 7 and 8 . These figures are obtained by fitting a kernel-weighted local polynomial smoothing to the data, with kernel=epanechnikov and degree $=1$.
} 

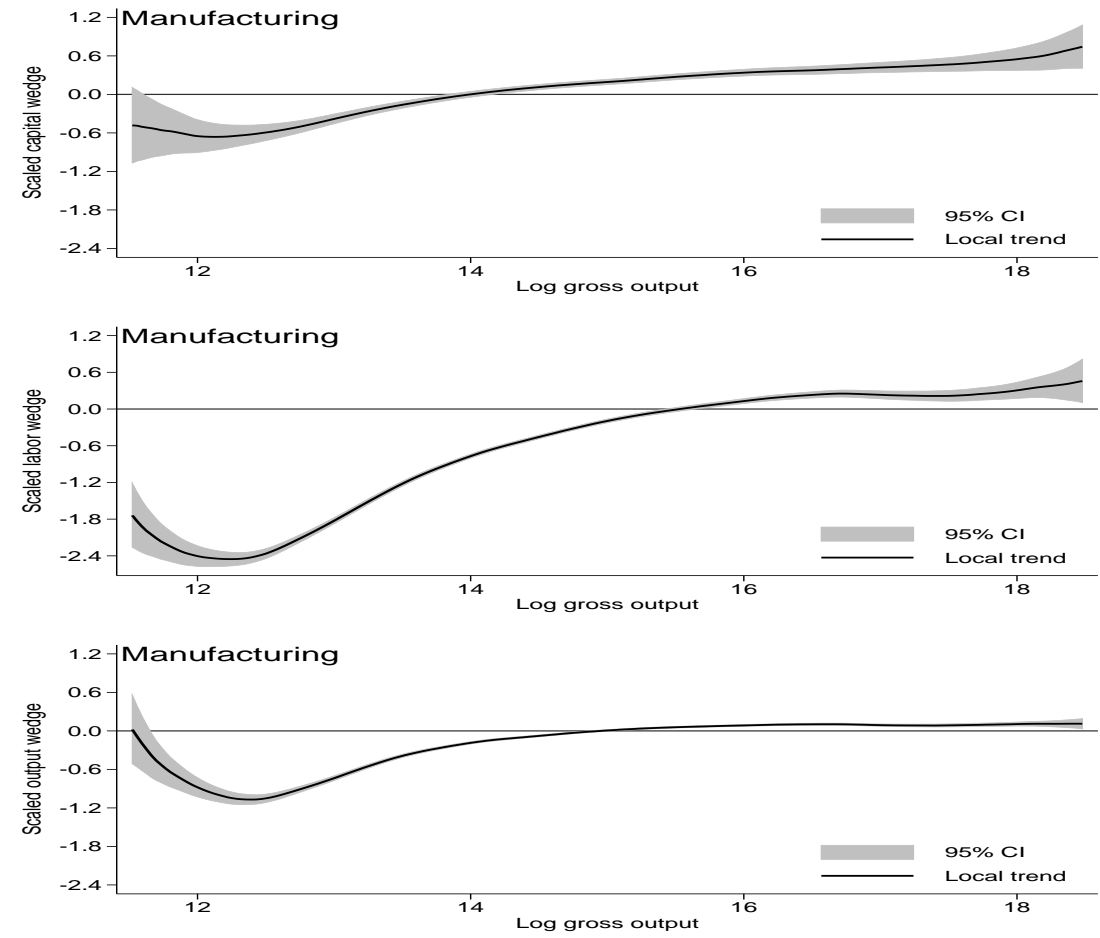

Figure 7: Manufacturing: Relationship between wedges and firms' size - 2011

firms' size and their TFPR is zero it means that firms producing more output do not face, on average, higher distortions leading to a higher value for scaled TFPR. From Figure6, we see that for the whole economy (upper panel) TFPR increases with size (in a non monotonic way) suggesting that, on average, small and medium-sized firms (firms for which scaled TFPR is negative) are benefiting from relatively smaller distortions. This pattern for the whole economy closely reproduces what happens in the service sector (bottom panel). The situation is distinct regarding the manufacturing sector: while TFPR increases with size for small firms, it is essentially uncorrelated with gross output for large and very large firms.

In order to investigate this issue further and identify the type of distortion prevailing in each case, we now look at the relationship between scaled TFPR and the wedges. From equations (11) and (17), we get:

$$
\ln \left(\frac{T F P R_{s i}}{T F P R_{s}^{*}}\right)=\alpha_{s} \log \left(\frac{1+\tau_{k_{s i}}}{1+\bar{\tau}_{k_{s}}}\right)+\beta_{s} \log \left(\frac{1+\tau_{h_{s i}}}{1+\bar{\tau}_{h_{s}}}\right)-\log \left(\frac{1-\tau_{y_{s i}}}{1-\bar{\tau}_{y_{s}}}\right)
$$



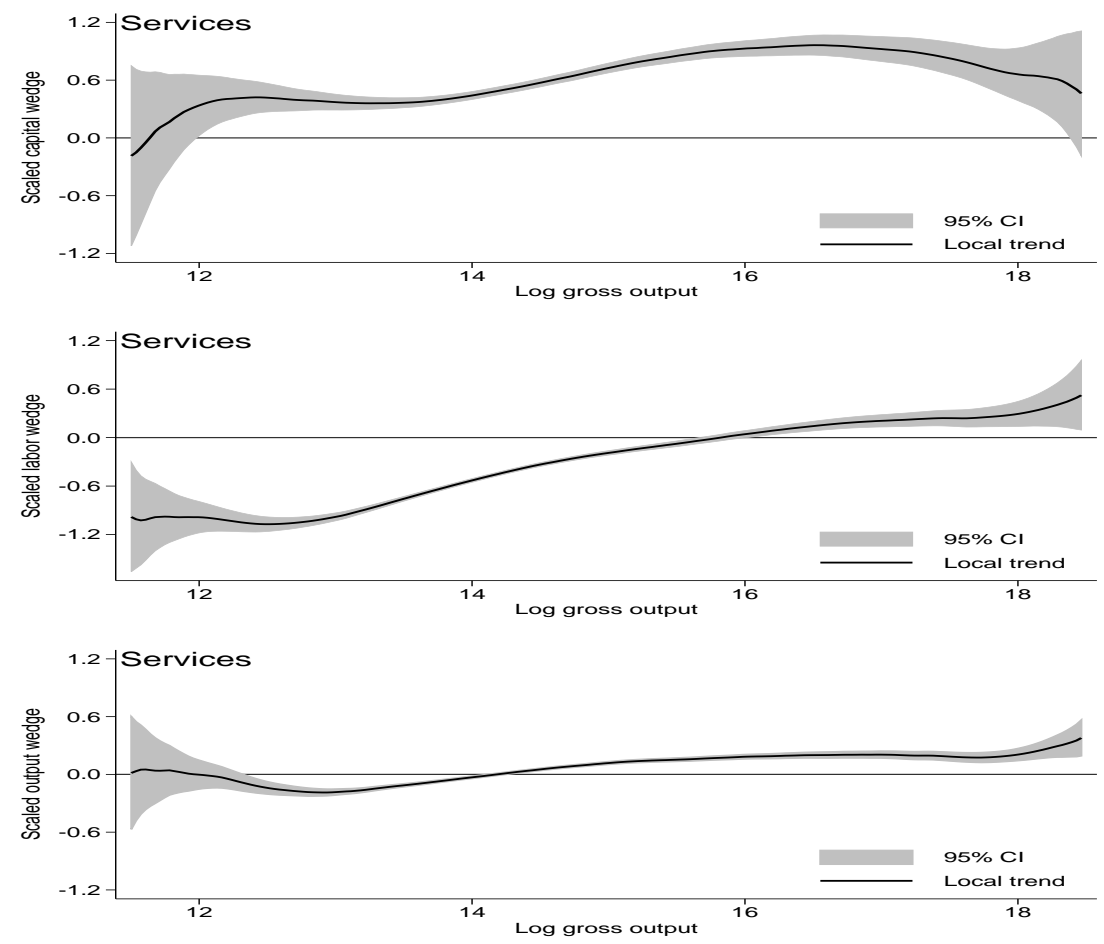

Figure 8: Services: Relationship between wedges and firms' size - 2011

where $\left(1+\bar{\tau}_{k_{s}}\right),\left(1+\bar{\tau}_{h_{s}}\right),\left(1-\bar{\tau}_{y_{s}}\right)$ stand for the average wedges in industry $s$ that would prevail in an efficient allocation of resources. Thus, equation (24) allows us to decompose the scaled TFPR for each firm as a weighted sum of the scaled capital, labor and output wedges.

From Figures 7 and 8, which depict the relationships between each individual scaled wedge and gross output for the manufacturing and service sectors in 2011, we see that the three wedges increase with size, suggesting that, on average, small and mediumsized firms benefit from lower capital and labor costs, but tend to face higher output distortions 25

In the Portuguese economy, capital distortions do not appear to affect small or medium-sized firms more heavily than they do to large firms, in contrast to what might be expected. Moreover, not only small but also medium-sized firms emerge as

\footnotetext{
${ }^{25}$ Note that if the scaled capital wedge or the scaled labor wedge are negative, the firm may be thought of as being subsidized, i.e., facing lower capital or lower labor costs than firms for which those wedges are positive. In contrast, firms for which the scaled output wedge is negative are facing higher output distortions, than firms for which it is positive.
} 
benefitting from lower labor costs. The fact that such firms, both in the manufacturing and service sectors, emerge as benefitting from lower capital and lower labor costs is in line with the idea that smaller and medium-sized firms in Portugal benefit from firm's size-contingent laws passed by the Portuguese Government that directly or indirectly reduce the costs of capital, as well as the costs of labor.

Our results are consistent with Braguinsky et al. (2011) who use matched employeremployee data to document that the Portuguese firm size distribution has been shifting to the left. They argue that Portugal's uniquely strong protections for regular workers - that can be seen as an effective tax on wages - have played an important role in this process. Our results also suggest that not only labor distortions but also capital distortions must have played a role in shaping the evolution of the Portuguese firm size distribution over the last fifteen years ${ }^{26}$

\section{Relative importance of distortions}

We now evaluate the relative importance of the three types of distortions for grossoutput and value-added gains. Table 8 reports the efficiency gains obtained by eliminating variation in one wedge at a time and fixing the quantity of the other two inputs (see Appendix B for details). Capital distortions emerge as the most important type of distortions, with increasing importance over the sample period. Eliminating variation in the capital wedge implies value-added gains for the whole economy of 18 percent in 1996, 25 percent in 2004 and 32 percent in 2011. The corresponding figures for the labor wedge, which emerges as the second most important distortion, are 12, 15 and 17 percent, respectively. Interestingly, when we look at sectoral disaggregation we notice that the general picture changes somewhat. In the manufacturing sector, capital and labor distortions have about the same importance in terms of implications for gross-output or value-added gains, while in the service sector, capital distortions

\footnotetext{
${ }^{26}$ Braguinsky et al. (2011) list a number of firm-size contingent laws passed by the Portuguese Government until 2005. Some examples: firms over 50 workers must maintain an internal worker health protection system; firms under 50 workers receive support for hiring workers; and firms under 250 workers have special lines of credit.
} 
have an impact about twice as large as labor distortions ${ }^{27}{ }^{28}$

Table 8: Relative importance of wedges

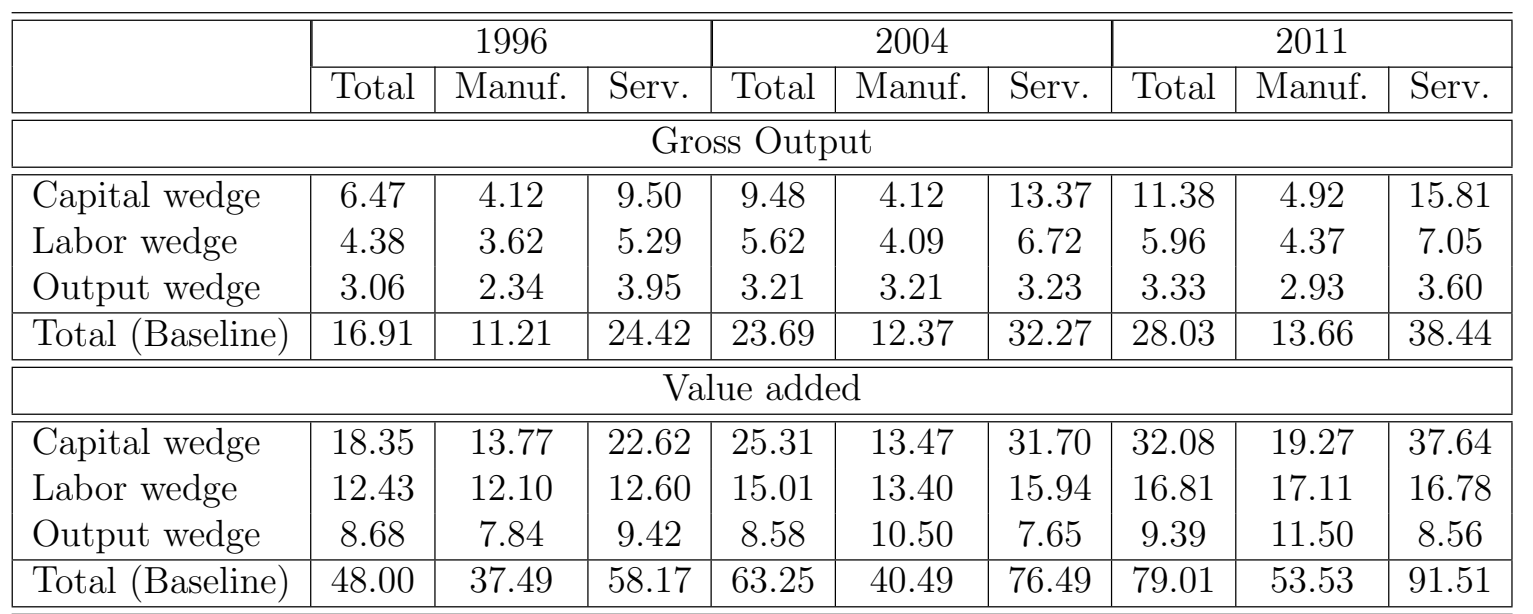

Note: Entries for each wedge are the gains obtained by eliminating variation in that wedge or distortion individually and fixing the quantity of the other inputs. Entries for the total correspond to the gains of eliminating variation in the three wedges simultaneously and are reproduced from Table 4 above. The labor input is measured by the wage bill $\left(H_{s i}=W_{s i} L_{s i}\right)$ and the intermediate input by $Q_{s i}=Z_{s} Q_{s i}$ with $Z_{s}=1$.

The evidence in this paper is consistent with the claim made in Reis $(2013)$. The author looks at the time pattern of sectoral productivity and employment and concludes that the Portuguese economic slump in the 2000's stems mainly from inefficiencies in the financial sector that caused capital inflows to be largely misallocated leading to an expansion of the country's unproductive nontradables at the expense of more productive tradables. Our paper is mute regarding the importance of misallocation across industries. However, the evidence on within-industry reallocation gains, recorded in

\footnotetext{
${ }^{27}$ The general picture regarding the relative importance of the three wedges does not change significantly when we look at the census of firms for the 2004-2011 period: the capital distortion is still by far the most important distortion on the aggregate, as well as in the service sector, while in the manufacturing sector the three distortions now play a similar role. However, the situation changes somewhat if we consider the case in which labor input is measured by employment. In this case, the relative importance of labor and capital distortions become about the same not only at the aggregate level but also at the sector level (manufacturing and services).

${ }^{28}$ We note that the reallocation gains obtained from adjusting one factor of production individually depend on the way the wedges are defined. In this paper we assumed that profits are given by equation (6). An alternative expression for the profit function would be $\pi_{s i}=P_{s i} Y_{s i}-\left(1+\tau_{k_{s i}}\right) R_{s} K_{s i}-$ $\left(1+\tau_{h_{s i}}\right) W_{s} H_{s i}-\left(1+\tau_{q_{s i}}\right) Z_{s} Q_{s i}$ where a wedge on intermediate inputs, $\tau_{q_{s i}}$, takes the place of the output wedge in equation (6). The two alternative parameterizations for the profit function deliver the same total reallocation gains, but the decomposition in terms of the individual contributions associated with each wedge are different. We took this into account and also computed the gains of reallocation associated with the individual wedges in this alternative specification for the profit function. The results are quantitatively slightly different, but qualitatively nothing changes - capital misallocation still emerges as the main source of overall misallocation. The derivations as well as the results are available from the authors upon request.
} 
Sections 4 and 5, shows that misallocation in the service sector is significantly higher and increased faster than in the manufacturing sector. In addition, the evidence in Table 8 suggests that misallocation in the service sector stems above all from capital distortions.

\section{Conclusions}

We use Portuguese firm-level data to investigate whether misallocation may have contributed to the poor economic performance of some southern and peripheral European countries in the run-up to the Eurozone crisis.

We find that the potential efficiency gains obtained from eliminating distortions in the economy and reallocating resources to the most efficient firms within industries are significant and have increased over time. Equalizing TFPR across firms within an industry could have boosted gross output 17 and 28 percent and valued-added 48 and 79 percent above actual levels in 1996 and 2011, respectively. These figures imply deteriorating allocative efficiency may have shaved around $0.6 \mathrm{pp}$ off annual gross output growth and 1.3 pp off annual GDP growth during the 1996-2011 period. This is significant given that the Portuguese GDP grew only 1.5 percent, on average, per year during this period.

We also find that the main driver of the deteriorating allocative efficiency in the Portuguese economy is the service sector. For 1996 and 2011, the potential efficient levels of value added in the service sector would be 58 percent and 92 percent above the actual value added, respectively. Capital distortions are more important than labor and output distortions in explaining potential value-added efficiency gains, especially in the service sector. Over time, the relative contribution of capital distortions for total efficiency gains increased from 46 percent in 1996 to 55 percent in 2011.

Construction, ground transportation, transportation support services (e.g., road and toll-road management and maintenance), general support services (accounting, 
law, market research, etc.) and wholesale of food and drinks emerge as the five most important industries responsible for the decline in allocative efficiency. On the positive side, production and distribution of electricity, rental cars, advertising, production of alcoholic and non-alcoholic drinks, and wholesale of raw materials stand out as the five most important industries where allocative efficiency has improved.

Smaller firms emerge as having, on average, benefitted from capital and labor subsidies. This suggests that a large portion of these firms may have survived because of access to cheaper credit and labor, either because they benefitted from firm sizecontingent laws passed by the Portuguese Government or because they managed to evade taxes or to circumvent some general labor and/or capital regulations. At the same time, these smaller firms also face larger output distortions, but in combination the distortions suggest that most of these firms should shrink in size.

Robustness checks suggest that our baseline results should be seen as conservative estimates. Alternative computations, namely those that result from using employment to measure the labor input or census data for the 2004-2011 period suggest that actual efficiency gains are likely to be well above the ones obtained from our baseline model. Taken altogether, our results suggest that papers restricting their attention to the manufacturing sector are likely to underestimate the importance of reallocation for the economy as a whole.

The reasons that might explain why within-industry misallocation has increased overtime in the Portuguese economy are not easily identifiable. The fact that an important part of the misallocation problems appears to be concentrated in the micro or small firms especially of the service sector, and that the importance of such firms has increased over time (Braguinsky et al. (2011)), probably because they benefitted from lower capital and labor costs, might help explain the observed time pattern of misallocation. Furthermore, the increasing importance of capital distortions suggests that the financial sector might have contributed to the survival of many small and relatively inefficient firms. This result is consistent with the message in Reis (2013), who 
argues that misallocation across sectors stemming from inefficiencies in the financial sector is the main responsible for the Portuguese economic slump during the 2000's. Still, we believe that further investigation is required in order to fully understand why misallocation increased in Portugal during that period.

Finally, while we believe that a similar pattern of deteriorating allocative efficiency might have occurred in the southern and peripheral Eurozone economies which experienced stagnant or decreasing productivity in the 2000's, this still needs to be verified. It will also be important to study how the global financial crisis affected misallocation, in particular if it had a cleansing or scarring effect and whether there were asymmetric sectoral effects. However, we leave these questions and others for future work.

\section{Appendix A: How does misallocation in Portugal compare with other countries?}

The empirical evidence on misallocation available in the literature for other countries has been obtained using a two-factor model on value added ${ }^{29}$ Therefore, in this Appendix, for comparability reasons, we briefly present and comment on the results for Portugal that we obtain when the two-factor model, as developed in Hsieh and Klenow (2009), is used 30

Table A1 reports measures of dispersion for scaled TFPR similar to the ones presented in Table 2. From these tables we see that the measures of dispersion for value added (Table A1) are generally higher than the corresponding measures for gross output (Table 2).

\footnotetext{
${ }^{20}$ Sandleris and Wright (2011) developed a three factor model for gross output, but their empirical results are not comparable to ours as they assume a different framework (e.g., perfect competition within each industry).

${ }^{30}$ Similar to the three-factor model in the main text, we set the elasticity of output (value added) with respect to capital in each industry $\left(\alpha_{s}\right)$ to be one minus the labor share in the corresponding sector in the United States.
} 
Table A1: Dispersion of TFPR

(Two-factor model: Value Added)

\begin{tabular}{|l|c|c|c|c|c|c|c|c|c|}
\hline \hline & \multicolumn{3}{|c|}{1996} & \multicolumn{3}{c|}{2004} & \multicolumn{3}{c|}{2011} \\
\cline { 2 - 10 } & Total & Manuf. & Serv. & Total & Manuf. & Serv. & Total & Manuf. & Serv. \\
\hline \hline S.D. & 0.42 & 0.39 & 0.45 & 0.40 & 0.36 & 0.42 & 0.48 & 0.42 & 0.50 \\
$75-25$ & 0.44 & 0.40 & 0.50 & 0.44 & 0.38 & 0.49 & 0.52 & 0.45 & 0.57 \\
$90-10$ & 0.97 & 0.87 & 1.05 & 0.93 & 0.80 & 1.02 & 1.10 & 0.95 & 1.18 \\
\hline
\end{tabular}

Note: Statistics are for $\ln \left(T F P R_{s i} / T F P R_{s}^{*}\right)$. S.D.=Standard deviation, $75-25$ is the difference between the 75 th and 25 th percentiles, and the $90-10$ the 90 th vs. 10 th percentiles.

Measures of dispersion for the manufacturing sector in Table A1 may be compared with similar measures obtained in the literature for other countries. Such measures suggest, for instance, that dispersion of scaled TFPR is lower in the Portuguese manufacturing sector than in the U.S.. For 1997, Hsieh and Klenow (2009) find 0.49, 0.53 and 1.19 for the three measures of dispersion reported in Table A1, respectively. For the same year, for Portugal, we find 0.40, 0.44 and 0.94. Slightly smaller dispersion measures than the ones presented in Hsieh and Klenow (2009) for the U.S., were also found in Bellone and Mallen-Pisano (2013) for the French manufacturing sector in the 1998-2005 period ${ }^{31}$ The measures of dispersion for the manufacturing sector in Table A1 are also clearly lower than the ones obtained for other countries for which there are comparable results such as Bolivia (Machicado and Birbuet (2012)), Colombia (Camacho and Conover (2010) $)$, India and China (Hsieh and Klenow (2009)), Chile (Chen and Irarrazabal (2013)) and most South-America countries (Busso et al. (2012)) 32

Table A2 reports the value-added efficiency gains computed from the two-factor model. Comparing Table 4 with Table A2, we see from Table 4 that, for instance, reallocation gains for the whole economy in 2011 are only about 28 percent in terms of gross output, but represent about 79 percent in terms of value added, well above the 51

\footnotetext{
${ }^{31}$ These comparisons must be interpreted with caution, given potential differences in the sampling processes. For instance, for Portugal and France data cover only units with more than 20 employees, while data for the US may encompass smaller units.

${ }^{32}$ Strictly speaking, statistics in Table A1 are not directly comparable to similar measures available in the literature, because the latter are for $\ln \left(T F P R_{s i} / \overline{T F P R}_{s}\right)$, where $\overline{T F P R}_{s}$ is the geometric average of the marginal revenue product of capital, labor and intermediate inputs in the industry (see Appendix B). The differences between the two are, however, negligible.
} 
percent gains delivered by the two-factor model. This result, which, as far as we know, is new in the literature, is very interesting. On the one hand, it is consistent with the idea that heterogeneity in productivity across firms within an industry appears significantly smaller when we look at gross output than at value added but, on the other hand, implies larger value-added efficiency gains than the two-factor model.

Table A2: Output gains from equalizing TFPR within industries (Two-factor model - Value-added gains)

\begin{tabular}{|c|c|c|c|c|}
\hline \hline Years & Total economy & Agriculture & Manufacturing & Services \\
\hline \hline 1996 & 34.51 & 36.58 & 28.88 & 39.79 \\
1999 & 33.14 & 33.06 & 26.06 & 38.59 \\
2004 & 36.82 & 33.08 & 26.05 & 42.29 \\
2008 & 52.45 & 40.45 & 32.66 & 61.16 \\
2011 & 51.09 & 42.87 & 37.50 & 56.72 \\
\hline \hline
\end{tabular}

Note: Entries are $\left(Y_{s}^{*} / Y_{s}-1\right) * 100$ and $\left(Y^{*} / Y-1\right)^{*} 100$, where $Y_{s}^{*} / Y_{s}$ and $Y^{*} / Y$ are given by the two-factor model equivalent for equations 19 and 20 , respectively. The labor input is measured by the wage bill $\left(H_{s i}=W_{s i} L_{s i}\right)$.

Ghandi et al. (2011)) suggested that smaller heterogeneity in gross-output productivity was likely to imply smaller relative efficiency gains than what the value-added approach developed in Hsieh and Klenow (2009) would suggest. The idea is that significantly smaller dispersion measures could imply much less room for improvement in aggregate productivity, so that the use of gross-output production functions would generate smaller differences in the estimates of misallocation across developed and developing countries as compared to the value-added approach that dominates the literature. The results above show, however, that this is not necessarily the case: small gross-output gains may imply large value-added gains, because these depend not only on heterogeneity in gross-output revenue productivity (which conditions gross-output efficiency gains), but also on the importance of intermediate inputs. In other words, the higher value-added efficiency gains in the three-factor model as compared to the two-factor model stem from the fact that the first approach allows for misallocation in intermediate inputs while the second does not 33

\footnotetext{
${ }^{33}$ To illustrate this point let us assume that gross output, $\mathrm{Y}$, is given by the Cobb-Douglas production
} 
A second important result in Table A2 is that misallocation also emerges as increasing over time when we look at the two-factor model. Again the service sector is the main responsible for the deterioration of allocative efficiency. According to Table A2, misallocation may have trimmed around 0.8 pp off annual GDP growth from 1996 to 2011.

An additional result that emerges from Table A2, regards the relative gains in the manufacturing sector versus the service sector. By comparing the reallocation gains for the manufacturing sector with those of the total economy, we conclude that the reallocation gains identified so far in the literature, to the extent that they are restricted to the manufacturing sector, are likely to underestimate the importance of reallocation gains for the whole economy.

Finally, from Table A2, we conclude that the efficiency gains for the manufacturing sector in the two-factor model are somewhat lower than the ones obtained for the U.S. in Hsieh and Klenow (2009), and similar to the ones obtained for France in Bellone and Mallen-Pisano (2013) 34 This evidence suggests some observations. First, these results are consistent with the idea that developing countries such as China, India and many South-American countries, suffer more from resource misallocation than developed ones like the U.S., France or Portugal. However, these figures are not consistent with the idea that the U.S. economy faces less misallocation than a typical European economy function $Y=A K^{\alpha} H^{\beta} Q^{1-\alpha-\beta}$ (as in equation (5)), and that a constant fraction of gross output, $\mu$, is used as an intermediate input, so that $\mathrm{Q}=\mu \mathrm{Y}$ and $\mathrm{V}=(1-\mu) \mathrm{Y}$ where $\mathrm{V}$ is value added. It is straightforward to show that the corresponding value-added production function is $V=\bar{A} K^{\bar{\alpha}} H^{1-\bar{\alpha}}$ where $\bar{A}=\left[A \mu^{1-\alpha-\beta}(1-\mu)^{\alpha+\beta}\right]^{1 /(\alpha+\beta)}$ and $\bar{\alpha}=\alpha /(\alpha+\beta)$. Thus, $\bar{A}$ (TFP in the value-added production function) depends not only on A (TFP in the gross-output production function) but also on the allocation of resources to intermediate inputs. $\bar{A}$ is maximized when $\mu=1-\alpha-\beta$, which is the optimal spending share on intermediate inputs in the absence of distortions (see equation (8) above). For any other spending share $\bar{A}$ will be lower and this effect will be amplified the higher is the intermediate inputs share. Thus, firms with high intermediate input shares that face significant distortions affecting intermediate inputs may emerge as low productivity firms (small $\bar{A}$ ) in the twofactor approach despite being highly productive firms (firms with a very large A).

${ }^{34}$ The efficiency gains for the U.S. computed in Hsieh and Klenow (2009) for 1997 are 42.9 percent, while those for France presented in Bellone and Mallen-Pisano (2013) are 30.5, 27.5 and 30.5 percent, for 1998,2001 , and 2005 respectively.

Using the Hsieh and Klenow (2009) methodology with the census of firms for the 2004-2011 period we get value-added reallocation gains for the manufacturing sector of 36 percent for 2004 and 48 percent for 2011. These figures still do not show a significant efficiency gap vis-à-vis the U.S. 
like France or Portugal, at least with respect to the manufacturing sector. Second, these results, to the extent that they suggest a low degree of within industry misallocation in the Portuguese manufacturing sector, are consistent with the conclusions in Duarte and Restuccia (2007), who investigated the process of structural transformation undertaken by Portugal between 1956 and 2005. The authors conclude that productivity growth in manufacturing accounts for most of the reduction of the aggregate productivity gap with the U.S. and that further closing of the gap can only be accomplished via improvements in the relative productivity in the service sector.

\section{Appendix B - Derivation of the main formulas}

In this appendix we show the derivation of some of the formulas presented in Section 2 and the equivalence between our formulas and the ones presented in Hsieh and Klenow (2009).

\section{B1 - Factor demand equations}

The factor demand equations are obtained from solving the firm cost minimization problem subject to a minimum production constraint,

$$
\min _{\left\{K_{s i}, H_{s i}, Q_{s i}\right\}}\left\{\begin{array}{l}
T C_{s i}=\left(1+\tau_{k_{s i}}\right) R_{s} K_{s i}+\left(1+\tau_{h_{s i}}\right) W_{s} H_{s i}+Z_{s} Q_{s i} \\
\text { s.t. } A_{s i} K_{s i}^{\alpha_{s}} H_{s i}^{\beta_{s}} Q_{s i}^{1-\alpha_{s}-\beta_{s}} \geq \bar{Y}_{s i}
\end{array}\right.
$$

From the first order conditions we get:

$$
\left\{\begin{array}{l}
K_{s i}:\left(1+\tau_{k_{s i}}\right) R_{s}=\theta \alpha_{s} \frac{\left(A_{s i} K_{s i}^{\alpha_{s}} H_{s i}^{\beta_{s}} Q_{s i}^{1-\alpha_{s}-\beta_{s}}\right)}{K_{s i}}=\theta \alpha_{s} \frac{\bar{Y}_{s i}}{K_{s i}} \\
H_{s i}:\left(1+\tau_{h_{s i}}\right) W_{s}=\theta \beta_{s} \frac{\left(A_{s i} K_{s i}^{\alpha_{s}} H_{s i}^{\beta_{s}} Q_{s i}^{1-\alpha_{s}-\beta_{s}}\right)}{H_{s i}}=\theta \beta_{s} \frac{\bar{Y}_{s i}}{H_{s i}} \\
Q_{s i}: Z_{s}=\theta\left(1-\alpha_{s}-\beta_{s}\right) \frac{\left(A_{s i} K_{s i}^{\alpha_{s}} H_{s i}^{\beta_{s}} Q_{s i}^{1-\alpha_{s}-\beta_{s}}\right)}{Q_{s i}}=\theta\left(1-\alpha_{s}-\beta_{s}\right) \frac{\bar{Y}_{s i}}{Q_{s i}} \\
\theta: A_{s i} K_{s i}^{\alpha_{s}} H_{s i}^{\beta_{s}} Q_{s i}^{1-\alpha_{s}-\beta_{s}}=\bar{Y}_{s i}
\end{array}\right.
$$

where $\theta$ is the lagrange multiplier. Solving this system we obtain the conditional factor demand functions: 


$$
\left\{\begin{array}{l}
K_{s i}=\left(\frac{\bar{Y}_{s i}}{A_{s i}}\right)\left(\frac{\left(1+\tau_{k_{s i}}\right)^{\alpha_{s}}\left(1+\tau_{h_{s i}}\right)^{\beta_{s}}}{\left(1+\tau_{k_{s i}}\right)}\right) \Psi_{s}\left(\frac{\alpha_{s}}{R_{s}}\right) \\
H_{s i}=\left(\frac{\bar{Y}_{s i}}{A_{s i}}\right)\left(\frac{\left(1+\tau_{k_{s i}}\right)^{\alpha_{s}}\left(1+\tau_{h_{s i}}\right)^{\beta_{s}}}{\left(1+\tau_{h_{s i}}\right)}\right) \Psi_{s}\left(\frac{\beta_{s}}{W_{s}}\right) \\
Q_{s i}=\left(\frac{\bar{Y}_{s i}}{A_{s i}}\right)\left(\left(1+\tau_{k_{s i}}\right)^{\alpha_{s}}\left(1+\tau_{h_{s i}}\right)^{\beta_{s}}\right) \Psi_{s}\left(\frac{\left(1-\alpha_{s}-\beta_{s}\right)}{Z_{s}}\right)
\end{array}\right.
$$

where

$$
\Psi_{s}=\left[\left(\frac{R_{s}}{\alpha_{s}}\right)^{\alpha_{s}}\left(\frac{W_{s}}{\beta_{s}}\right)^{\beta_{s}}\left(\frac{Z_{s}}{1-\alpha_{s}-\beta_{s}}\right)^{1-\alpha_{s}-\beta_{s}}\right]
$$

These demand functions imply the following total cost function:

$$
\begin{aligned}
T C_{s i} & =\left(1+\tau_{k_{s i}}\right) R_{s} K_{s i}+\left(1+\tau_{h_{s i}}\right) W_{s} H_{s i}+Z_{s} Q_{s i} \\
& =\left(\frac{\bar{Y}_{s i}}{A_{s i}}\right)\left(1+\tau_{k_{s i}}\right)^{\alpha_{s}}\left(1+\tau_{h_{s i}}\right)^{\beta_{s}} \Psi_{s}
\end{aligned}
$$

We may now obtain the formula for the level of output, $Y_{s i}$, produced by the firm given its specific wedges and the industry factor prices. This is the solution to the profit maximization problem:

$$
\max \left\{\left(1-\tau_{y_{s i}}\right) Y_{s i}^{\frac{\sigma-1}{\sigma}}-T C_{s i}\right\}
$$

which is given by:

$$
Y_{s i}=\left(\frac{\sigma-1}{\sigma} \frac{A_{s i}}{\Psi_{s}} \frac{\left(1-\tau_{y_{s i}}\right)}{\left(1+\tau_{k_{s i}}\right)^{\alpha_{s}}\left(1+\tau_{h_{s i}}\right)^{\beta_{s}}}\right)^{\sigma}
$$

If we replace $Y_{s i}$ in the conditional factor demand equations that were obtained above, we get the profit maximizing factor demands:

$$
\left\{\begin{array}{l}
K_{s i}=\left(\frac{\sigma-1}{\sigma}\left(1-\tau_{y_{s i}}\right)\right)^{\sigma}\left(\frac{A_{s i}}{\Psi_{s}\left(1+\tau_{k_{s i}}\right)^{\alpha_{s}}\left(1+\tau_{h_{s i}}\right)^{\beta_{s}}}\right)^{\sigma-1}\left(\frac{\alpha_{s}}{\left(1+\tau_{k_{s i}}\right) R_{s}}\right) \\
H_{s i}=\left(\frac{\sigma-1}{\sigma}\left(1-\tau_{y_{s i}}\right)\right)^{\sigma}\left(\frac{A_{s i}}{\Psi_{s}\left(1+\tau_{k_{s i}}\right)^{\alpha_{s}}\left(1+\tau_{h_{s i}}\right)^{\beta_{s}}}\right)^{\sigma-1}\left(\frac{\beta_{s}}{\left(1+\tau_{h_{s i}}\right) W_{s}}\right) \\
Q_{s i}=\left(\frac{\sigma-1}{\sigma}\left(1-\tau_{y_{s i}}\right)\right)^{\sigma}\left(\frac{A_{s_{i}}}{\Psi_{s}\left(1+\tau_{k_{s i}}\right)^{\alpha_{s}}\left(1+\tau_{h_{s i}}\right)^{\beta_{s}}}\right)^{\sigma-1}\left(\frac{\left(1-\alpha_{s}-\beta_{s}\right)}{Z_{s}}\right)
\end{array}\right.
$$




\section{B2 - Derivation of the industry average wedges}

As defined in Section 2, the industry average wedges are such that they are the same for all firms and the demand for factors of production at the industry level is the same before and after the reallocation of resources. Let $K_{s}, H_{s}$ and $Q_{s}$ denote the total amount of capital, labor and intermediate inputs used at the industry level, i.e., $K_{s}=\sum_{i=1}^{M_{s}} K_{s i}, H_{s}=\sum_{i=1}^{M_{s}} H_{s i}$ and $Q_{s}=\sum_{i=1}^{M_{s}} Q_{s i}$. Using the profit maximizing factor demand equations derived above we can write the total demand for each factor of production at the industry level as follows:

$$
\left\{\begin{array}{l}
K_{s}=\sum_{i=1}^{M_{s}}\left\{\left(\frac{\sigma-1}{\sigma}\left(1-\tau_{y_{s i}}\right)\right)^{\sigma}\left(\frac{A_{s i}}{\Psi_{s}\left(1+\tau_{k_{s i}}\right)^{\alpha_{s}}\left(1+\tau_{h_{s i}}\right)^{\beta_{s}}}\right)^{\sigma-1}\left(\frac{\alpha_{s}}{\left(1+\tau_{k_{s i}}\right) R_{s}}\right)\right\} \\
H_{s}=\sum_{i=1}^{M_{s}}\left\{\left(\frac{\sigma-1}{\sigma}\left(1-\tau_{y_{s i}}\right)\right)^{\sigma}\left(\frac{A_{s i}}{\Psi_{s}\left(1+\tau_{k_{s i}}\right)^{\alpha_{s}}\left(1+\tau_{h_{s i}}\right)^{\beta_{s}}}\right)^{\sigma-1}\left(\frac{\beta_{s}}{\left(1+\tau_{h_{s i}}\right) W_{s}}\right)\right\} \\
Q_{s}=\sum_{i=1}^{M_{s}}\left\{\left(\frac{\sigma-1}{\sigma}\left(1-\tau_{y_{s i}}\right)\right)^{\sigma}\left(\frac{A_{s i}}{\Psi_{s}\left(1+\tau_{k_{s i}}\right)^{\alpha_{s}}\left(1+\tau_{h_{s i}}\right)^{\beta_{s}}}\right)^{\sigma-1}\left(\frac{\left(1-\alpha_{s}-\beta_{s}\right)}{Z_{s}}\right)\right\}
\end{array}\right.
$$

If we replace $\left(1+\tau_{k_{s i}}\right),\left(1+\tau_{h_{s i}}\right)$ and $\left(1-\tau_{y_{s i}}\right)$ by the corresponding industry average wedges, $\left(1+\bar{\tau}_{k_{s}}\right),\left(1+\bar{\tau}_{h_{s}}\right)$ and $\left(1-\bar{\tau}_{y_{s}}\right)$, we obtain:

$$
\begin{aligned}
& \left\{\begin{array}{l}
K_{s}=\sum_{i=1}^{M_{s}}\left\{\left(\frac{\sigma-1}{\sigma}\left(1-\bar{\tau}_{y_{s}}\right)\right)^{\sigma}\left(\frac{A_{s i}}{\Psi_{s}\left(1+\bar{\tau}_{k_{s}}\right)^{\alpha_{s}}\left(1+\bar{\tau}_{h_{s}}\right)^{\beta_{s}}}\right)^{\sigma-1}\left(\frac{\alpha_{s}}{\left(1+\bar{\tau}_{k_{s}}\right) R_{s}}\right)\right\} \\
H_{s}=\sum_{i=1}^{M_{s}}\left\{\begin{array}{l}
\left.\left(\frac{\sigma-1}{\sigma}\left(1-\bar{\tau}_{y_{s}}\right)\right)^{\sigma}\left(\frac{A_{s i}}{\Psi_{s}\left(1+\bar{\tau}_{k_{s}}\right)^{\alpha_{s}}\left(1+\bar{\tau}_{h_{s}}\right)^{\beta_{s}}}\right)^{\sigma-1}\left(\frac{\beta_{s}}{\left(1+\bar{\tau}_{h_{s}}\right) W_{s}}\right)\right\} \\
Q_{s}=\sum_{i=1}^{M_{s}}\left\{\left(\frac{\sigma-1}{\sigma}\left(1-\bar{\tau}_{y_{s}}\right)\right)^{\sigma}\left(\frac{A_{s i}}{\Psi_{s}\left(1+\bar{\tau}_{k_{s}}\right)^{\alpha_{s}}\left(1+\bar{\tau}_{h_{s}}\right)^{\beta_{s}}}\right)^{\sigma-1}\left(\frac{\left(1-\alpha_{s}-\beta_{s}\right)}{Z_{s}}\right)\right\}
\end{array}\right\}
\end{array}\right. \\
& \left\{\begin{array}{l}
K_{s}=\left(\frac{\sigma-1}{\sigma}\left(1-\bar{\tau}_{y_{s}}\right)\right)^{\sigma}\left(\frac{1}{\Psi_{s}\left(1+\bar{\tau}_{k_{s}}\right)^{\alpha_{s}}\left(1+\bar{\tau}_{h_{s}}\right)^{\beta_{s}}}\right)^{\sigma-1}\left(\frac{\alpha_{s}}{\left(1+\bar{\tau}_{k_{s}}\right) R_{s}}\right) \sum_{i=1}^{M_{s}} A_{s i}^{\sigma-1} \\
H_{s}=\left(\frac{\sigma-1}{\sigma}\left(1-\bar{\tau}_{y_{s}}\right)\right)^{\sigma}\left(\frac{1}{\Psi_{s}\left(1+\bar{\tau}_{k_{s}}\right)^{\alpha_{s}}\left(1+\bar{\tau}_{h_{s}}\right)^{\beta_{s}}}\right)^{\sigma-1}\left(\frac{\beta_{s}}{\left(1+\bar{\tau}_{h_{s}}\right) W_{s}}\right) \sum_{i=1}^{M_{s}} A_{s i}^{\sigma-1} \\
Q_{s}=\left(\frac{\sigma-1}{\sigma}\left(1-\bar{\tau}_{y_{s}}\right)\right)^{\sigma}\left(\frac{1}{\Psi_{s}\left(1+\bar{\tau}_{k_{s}}\right)^{\alpha_{s}}\left(1+\bar{\tau}_{h_{s}}\right)^{\beta_{s}}}\right)^{\sigma-1}\left(\frac{\left(1-\alpha_{s}-\beta_{s}\right)}{Z_{s}}\right) \sum_{i=1}^{M_{s}} A_{s i}^{\sigma-1}
\end{array}\right.
\end{aligned}
$$

After some manipulation, we obtain:

$$
\left\{\begin{array}{l}
\left(1+\bar{\tau}_{k_{s}}\right)=\left(\frac{\alpha_{s}}{1-\alpha_{s}-\beta_{s}}\right) \frac{Z_{s} Q_{s}}{R_{s} K_{s}} \\
\left(1+\bar{\tau}_{h_{s}}\right)=\left(\frac{\beta_{s}}{1-\alpha_{s}-\beta_{s}}\right) \frac{Z_{s} Q_{s}}{W_{s} H_{s}} \\
\left(1-\bar{\tau}_{y_{s}}\right)=\left(\frac{\sigma}{\sigma-1}\right)\left(\frac{Z_{s} Q_{s}}{1-\alpha_{s}-\beta_{s}}\right)\left(\frac{1}{K_{s}^{\alpha_{s}} H_{s}^{\beta_{s}} Q_{s}^{1-\alpha_{s}-\beta_{s}}}\right)\left(\frac{K_{s}^{\alpha_{s}} H_{s}^{\beta_{s}} Q_{s}^{1-\alpha_{s}-\beta_{s}}}{\sum_{i=1}^{M_{s}} A_{s i}^{\sigma-1}}\right)^{\frac{1}{\sigma}}
\end{array}\right.
$$


Finally, we notice that by equation (18) we have

$$
\left(\frac{K_{s}^{\alpha_{s}} H_{s}^{\beta_{s}} Q_{s}^{1-\alpha_{s}-\beta_{s}}}{\sum_{i=1}^{M_{s}} A_{s i}^{\sigma-1}}\right)^{\frac{1}{\sigma}}=\frac{\left(K_{s}^{\alpha_{s}} H_{s}^{\beta_{s}} Q_{s}^{1-\alpha_{s}-\beta_{s}}\right)}{\left(P_{s} Y_{s}\right)^{*}}
$$

so that $\left(1-\bar{\tau}_{y_{s}}\right)$ may further be written as:

$$
\left(1-\bar{\tau}_{y_{s}}\right)=\left(\frac{\sigma}{\sigma-1}\right)\left(\frac{Z_{s} Q_{s}}{1-\alpha_{s}-\beta_{s}}\right) \frac{1}{\left(P_{s} Y_{s}\right)^{*}}
$$

which is the definition used in equation (16).

\section{B3 - Alternative derivation of $T F P R_{s}^{*}$}

In Section 2, we derived the expression for $T F P R_{s}^{*}$ (equation (18)) by imposing average wedges that lead to the same industry factor demands as those observed in the sample. Here we derive the expression for $T F P R_{s}^{*}$ following an alternative route in order to show that the same formula could have been obtained by just developing the definition for $T F P R_{s}^{*}$ :

$$
\begin{aligned}
\operatorname{TFPR}_{s}^{*} & =\frac{\left(P_{s} Y_{s}\right)^{*}}{\left(K_{s}^{\alpha_{s}} H_{s}^{\beta_{s}} Q_{s}^{1-\alpha_{s}-\beta_{s}}\right)}=\frac{\sum_{i=1}^{M_{s}}\left(P_{s i} Y_{s i}\right)^{*}}{\left(K_{s}^{\alpha_{s}} H_{s}^{\beta_{s}} Q_{s}^{1-\alpha_{s}-\beta_{s}}\right)} \\
& =\frac{\sum_{i=1}^{M_{s}}\left(\frac{A_{s i}}{T F P R_{s}^{*}}\right)^{\sigma-1}}{\left(K_{s}^{\alpha_{s}} H_{s}^{\beta_{s}} Q_{s}^{1-\alpha_{s}-\beta_{s}}\right)}=\left[\frac{\sum_{i=1}^{M_{s}} A_{s i}^{\sigma-1}}{\left(K_{s}^{\alpha_{s}} H_{s}^{\beta_{s}} Q_{s}^{1-\alpha_{s}-\beta_{s}}\right)}\right]^{\frac{1}{\sigma}}
\end{aligned}
$$

which corresponds to equation (18).

\section{B4 - Equivalence between our formulas and Hsieh and Klenow (2009)}

Here we compare our formulas with the ones obtained in Hsieh and Klenow (2009) who follow a different route in deriving their formulas for the two-factor model. Defining 
sector aggregate $T F P_{s}$ as (adjusted for a three-factor model):

$$
T F P_{s}=\frac{Y_{s}}{K_{s}^{\alpha_{s}} H_{s}^{\beta_{s}} Q_{s}^{1-\alpha_{s}-\beta_{s}}}
$$

Hsieh and Klenow (2009, 2011) show that TFP may be written as

$$
\text { TFP }_{s}=\left[\sum_{i=1}^{M_{s}}\left(A_{s i} \frac{\overline{T F P R}_{s}}{T F P R_{s i}}\right)^{\sigma-1}\right]^{\frac{1}{\sigma-1}}
$$

where $\overline{T F P R}_{s}$ is given by:

$$
\begin{aligned}
\overline{T F P R_{s}}= & \frac{\sigma}{\sigma-1}\left[\frac{R_{s}}{\alpha_{s} \sum_{i=1}^{M_{s}}\left(\frac{1-\tau_{y_{s i}}}{1+\tau_{k_{s i}}}\right) \frac{P_{s i} Y_{s i}}{P_{s} Y_{s}}}\right]^{\alpha_{s}}\left[\frac{W_{s}}{\beta_{s} \sum_{i=1}^{M_{s}}\left(\frac{1-\tau_{y_{s i}}}{1+\tau_{l s i}}\right) \frac{P_{s i} Y_{s i}}{P_{s} Y_{s}}}\right]^{\beta_{s}} \\
& \times\left[\frac{Z_{s}}{\left(1-\alpha_{s}-\beta_{s}\right) \sum_{i=1}^{M_{s}}\left(1-\tau_{y_{s i}}\right) \frac{P_{s i} Y_{s i}}{P_{s} Y_{s}}}\right]^{1-\alpha_{s}-\beta_{s}}
\end{aligned}
$$

Equation for $T F P_{s}$ above shows that in the presence of distortions, sectoral TFP is itself distorted as it depends on the firms absolute physical productivities and on their relative revenue productivities. Indeed, high productivity firms which confront distortions (i.e., firms characterized by both high TFPQ and TFPR) will be smaller than optimal. In contrast, low productivity firms which benefit from subsidies (i.e., the ones characterized by both low TFPQ and low TFPR) will be larger than optimal.

From the equation for $T F P_{s}$ it is easy to show that aggregate gains may be computed from (Hsieh and Klenow (2009), equation (20)):

$$
\frac{Y}{Y^{*}}=\prod_{s=1}^{S}\left[\frac{T F P_{s}}{T F P_{s}^{*}}\right]^{\theta_{s}}=\prod_{s=1}^{S}\left[\sum_{i=1}^{M_{s}}\left(\frac{A_{s i}}{\bar{A}_{s}} \frac{\overline{T F P R}_{s}}{T F P R_{s i}}\right)^{\sigma-1}\right]^{\frac{\theta_{s}}{\sigma-1}}
$$

where $\bar{A}_{s}=T F P_{s}^{*}$ is the industry level efficient TFP given by

$$
T F P_{s}^{*}=\bar{A}_{s}=\left(\sum_{i=1}^{M_{s}} A_{s i}^{\sigma-1}\right)^{\frac{1}{\sigma-1}}
$$


which results when marginal products are equalized across firms.

We now show that equation 20 and the equation for $\frac{Y}{Y^{*}}$ above, derived in Hsieh and Klenow (2009), deliver the same result for reallocation gains as the two are just the inverse of each other. Taking just the industry $S$ component from equation (19) and replacing $T F P R^{*}$ by ist expression given by equation $(18)$ we have:

$$
\begin{aligned}
& \frac{Y_{s}^{*}}{Y_{s}}=\left[\frac{\sum_{i=1}^{M_{s}} A_{s i}^{\sigma-1}}{\sum_{i=1}^{M_{s}}\left(A_{s i} \frac{T F P R_{s}^{*}}{T F P R_{s i}}\right)^{\sigma-1}}\right]^{\frac{\sigma}{\sigma-1}}=\left[\frac{\sum_{i=1}^{M_{s}} A_{s i}^{\sigma-1}}{\sum_{i=1}^{M_{s}}\left(\left[\frac{\sum_{i=1}^{M_{s}} A_{s i}^{\sigma-1}}{\left(K_{s}^{\alpha_{s}} H_{s}^{\beta_{s}} Q_{s}^{1-\alpha_{s}-\beta_{s}}\right)}\right]^{\frac{1}{\sigma}} \frac{A_{s i}}{T F P R_{s i}}\right)^{\sigma-1}}\right]^{\frac{\sigma}{\sigma-1}} \\
& \left(\sum_{i=1}^{M_{s}} A_{s i}^{\sigma-1}\right)^{\frac{\sigma}{\sigma-1}} \\
& =\frac{\left[\left(\sum_{i=1}^{M_{s}} A_{s i}^{\sigma-1}\right)^{\frac{\sigma-1}{\sigma}} \sum_{i=1}^{M_{s}}\left(\left[\frac{\left(\frac{A_{s i}}{T F P R_{s i}}\right)^{\sigma}}{\left(K_{s}^{\alpha_{s}} H_{s}^{\beta_{s}} Q_{s}^{1-\alpha_{s}-\beta_{s}}\right)}\right]^{\frac{1}{\sigma}}\right)^{\sigma-1}\right]^{\frac{\sigma}{\sigma-1}}}{[}= \\
& =\frac{\left(\sum_{i=1}^{M_{s}} A_{s i}^{\sigma-1}\right)^{\frac{\sigma}{\sigma-1}}}{\left(\sum_{i=1}^{M_{s}} A_{s i}^{\sigma-1}\right) \frac{\left[\sum_{i=1}^{M_{s}}\left(\frac{A_{s i}}{T F P R_{s i}}\right)^{\sigma-1}\right]^{\frac{\sigma}{\sigma-1}}}{\left(K_{s}^{\alpha_{s}} H_{s}^{\beta_{s}} Q_{s}^{1-\alpha_{s}-\beta_{s}}\right)}}=\frac{\left(\sum_{i=1}^{M_{s}} A_{s i}^{\sigma-1}\right)^{\frac{1}{\sigma-1}}}{\frac{\left[\sum_{i=1}^{M_{s}}\left(\frac{A_{s i}}{T F P R_{s i}}\right)^{\sigma-1}\right]^{\frac{\sigma}{\sigma-1}}}{\left(K_{s}^{\alpha_{s}} H_{s}^{\beta_{s}} Q_{s}^{1-\alpha_{s}-\beta_{s}}\right)}} \\
& =\frac{\left(\sum_{i=1}^{M_{s}} A_{s i}^{\sigma-1}\right)^{\frac{1}{\sigma-1}}}{\frac{\left[\sum_{i=1}^{M_{s}}\left(Y_{s i}\right)^{\frac{\sigma}{\sigma-1}}\right]^{\frac{\sigma}{\sigma-1}}}{\left(K_{s}^{\alpha_{s}} H_{s}^{\beta_{s}} Q_{s}^{1-\alpha_{s}-\beta_{s}}\right)}}=\frac{\bar{A}_{s}}{\frac{Y_{s}}{\left(K_{s}^{\alpha_{s}} H_{s}^{\beta_{s}} Q_{s}^{1-\alpha_{s}-\beta_{s}}\right)}}=\frac{\bar{A}_{s}}{T F P_{s}}=\frac{T F P_{s}^{*}}{T F P_{s}}
\end{aligned}
$$

This implies that:

$$
\begin{aligned}
\frac{Y^{*}}{Y} & =\prod_{s=1}^{S}\left\{\left[\frac{\sum_{i=1}^{M_{s}} A_{s i}^{\sigma-1}}{\sum_{i=1}^{M_{s}}\left(A_{s i} \frac{T F P R_{s}^{*}}{T F P R_{s i}}\right)^{\sigma-1}}\right]^{\frac{\sigma}{\sigma-1}}\right\}^{\theta_{s}} \\
& =\prod_{s=1}^{S}\left\{\frac{\bar{A}_{s}}{T F P_{s}}\right\}^{\theta_{s}}=\left(\prod_{s=1}^{S}\left\{\frac{T F P_{s}}{\bar{A}_{s}}\right\}^{\theta_{s}}\right)^{-1}=\left(\frac{Y}{Y^{*}}\right)^{-1}
\end{aligned}
$$

\section{B5 - Importance of individual distortions}

To calculate the importance of the different distortions in Section 6 we fix two of the factors of production and allow the optimal reallocation of the third one. This is 
equivalent to finding an average wedge that is the same across firms in a given industry, which leads to an aggregate demand of that factor equal to the one observed in the sample. Let $\left(1+\widetilde{\tau}_{k_{s}}\right),\left(1+\widetilde{\tau}_{h_{s}}\right),\left(1-\widetilde{\tau}_{y_{s}}\right)$ be such wedges and $\widetilde{K}_{s i}, \widetilde{H}_{s i}$ and $\widetilde{Q}_{s i}$ denote the new allocation of resources that satisfy our criteria. We have:

$$
\begin{aligned}
\widetilde{K}_{s i} & =\frac{K_{s}}{Q_{s}} Q_{s i} \\
\widetilde{H}_{s i} & =\frac{H_{s}}{Q_{s}} Q_{s i} \\
\widetilde{Q}_{s i} & =Q_{s} \frac{\left[\left(A_{s i} K_{s i}^{\alpha_{s}} H_{s i}^{\beta_{s}}\right)^{\frac{\sigma-1}{\sigma}}\right]^{\frac{\sigma}{\sigma-\left(1-\alpha_{s}-\beta_{s}\right)(\sigma-1)}}}{\sum_{i=1}^{M_{s}}\left[\left(A_{s i} K_{s i}^{\alpha_{s}} H_{s i}^{\beta_{s}}\right)^{\frac{\sigma-1}{\sigma}}\right]^{\frac{\sigma}{\sigma-\left(1-\alpha_{s}-\beta_{s}\right)(\sigma-1)}}}
\end{aligned}
$$

where, as before, $K_{s}, H_{s}$ and $Q_{s}$ denote the observed amounts of capital, labor and intermediate inputs used in industry $s$.

We start by deriving the solution for the case of the capital distortion. From equations (8) we have:

$$
K_{s i}=\frac{\alpha_{s}}{\left(1-\alpha_{s}-\beta_{s}\right)} \frac{Z_{s} Q_{s i}}{R_{s}\left(1+\tau_{k_{s i}}\right)}
$$

so that we may write:

$$
\widetilde{K}_{s i}=\frac{\alpha_{s}}{\left(1-\alpha_{s}-\beta_{s}\right)} \frac{Z_{s} Q_{s i}}{R_{s}\left(1+\widetilde{\tau}_{k_{s}}\right)}
$$

From the industry aggregate condition:

$$
K_{s}=\sum_{i=1}^{M_{s}} \widetilde{K}_{s i}=\sum_{i=1}^{M_{s}} \frac{\alpha_{s}}{\left(1-\alpha_{s}-\beta_{s}\right)} \frac{Z_{s} Q_{s i}}{R_{s}\left(1+\widetilde{\tau}_{k_{s}}\right)}
$$

we get:

$$
\left(1+\widetilde{\tau}_{k_{s}}\right)=\frac{\alpha_{s}}{\left(1-\alpha_{s}-\beta_{s}\right)} \frac{Z_{s} Q_{s}}{R_{s} K_{s}}
$$


Substituting $\left(1+\widetilde{\tau}_{k_{s}}\right)$ into the expression for $\widetilde{K}_{s i}$ we obtain the final result presented above. The result for $\widetilde{H}_{s i}$ is similarly obtained. The derivation for $\widetilde{Q}_{s i}$ follows the same steps but the algebra is somewhat more complicated. From equations (8) we must have:

$$
\begin{aligned}
\left(1-\widetilde{\tau}_{y_{s}}\right) & =\frac{\sigma}{\sigma-1} \frac{1}{\left(1-\alpha_{s}-\beta_{s}\right)} \frac{Z_{s} \widetilde{Q}_{s i}}{\left(\widetilde{\left.P_{s i} Y_{s i}\right)}\right.}=\frac{\sigma}{\sigma-1} \frac{1}{\left(1-\alpha_{s}-\beta_{s}\right)} \frac{Z_{s} \widetilde{Q}_{s i}}{\left.\widetilde{(Y}_{s i}\right)^{\frac{\sigma-1}{\sigma}}} \\
& =\frac{\sigma}{\sigma-1} \frac{1}{\left(1-\alpha_{s}-\beta_{s}\right)} \frac{Z_{s} \widetilde{Q}_{s i}}{\left(A_{s i} K_{s i}^{\alpha_{s}} H_{s i}^{\beta_{s}} \widetilde{Q}_{s i}^{1-\alpha_{s}-\beta_{s}}\right)^{\frac{\sigma-1}{\sigma}}}
\end{aligned}
$$

Now, solving for $\widetilde{Q}_{s i}$ we get:

$$
\widetilde{Q}_{s i}=\left\{\frac{\sigma}{\sigma-1} \frac{1}{\left(1-\alpha_{s}-\beta_{s}\right)} \frac{Z_{s}}{\left(A_{s i} K_{s i}^{\alpha_{s}} H_{s i}^{\beta_{s}}\right)^{\frac{\sigma-1}{\sigma}}\left(1-\widetilde{\tau}_{y_{s}}\right)}\right\}^{\frac{\sigma}{(\sigma-1)\left(1-\alpha_{s}-\beta_{s}\right)-\sigma}}
$$

From the industry aggregate condition:

$$
Q_{s}=\sum_{i=1}^{M_{s}} \widetilde{Q}_{s i}=\sum_{i=1}^{M_{s}}\left\{\frac{\sigma}{\sigma-1} \frac{1}{\left(1-\alpha_{s}-\beta_{s}\right)} \frac{Z_{s}}{\left(A_{s i} K_{s i}^{\alpha_{s}} H_{s i}^{\beta_{s}}\right)^{\frac{\sigma-1}{\sigma}}\left(1-\widetilde{\tau}_{y_{s}}\right)}\right\}^{\frac{\sigma}{(\sigma-1)\left(1-\alpha_{s}-\beta_{s}\right)-\sigma}}
$$

we can solve for $\left(1-\widetilde{\tau}_{y_{s}}\right)$ :

$$
\begin{aligned}
\left(1-\widetilde{\tau}_{y_{s}}\right)= & \left(\frac{1}{Q_{s}}\right)^{\frac{(\sigma-1)\left(1-\alpha_{s}-\beta_{s}\right)-\sigma}{\sigma}}\left(\frac{\sigma}{\sigma-1} \frac{Z_{s}}{\left(1-\alpha_{s}-\beta_{s}\right)}\right) \\
& \times\left\{\sum_{i=1}^{M_{s}}\left(\frac{1}{\left(A_{s i} K_{s i}^{\alpha_{s}} H_{s i}^{\beta_{s}}\right)^{\frac{\sigma-1}{\sigma}}}\right)^{\frac{\sigma}{(\sigma-1)\left(1-\alpha_{s}-\beta_{s}\right)-\sigma}}\right\}^{\frac{(\sigma-1)\left(1-\alpha_{s}-\beta_{s}\right)-\sigma}{\sigma}}
\end{aligned}
$$

Finally, substituting $\left(1-\widetilde{\tau}_{y_{s}}\right)$ into the expression for $\widetilde{Q}_{s i}$ we obtain the final result presented above. 
After obtaining $\widetilde{K}_{s i}, \widetilde{H}_{s i}$ and $\widetilde{Q}_{s i}$, we can calculate the new output:

$$
\begin{aligned}
& \tilde{Y}_{s i}^{K}=Y_{s i}\left(\frac{\widetilde{K}_{s i}}{K_{s i}}\right)^{\alpha_{s}} \\
& \widetilde{Y}_{s i}^{H}=Y_{s i}\left(\frac{\widetilde{H}_{s i}}{H_{s i}}\right)^{\beta_{s}} \\
& \widetilde{Y}_{s i}^{Q}=Y_{s i}\left(\frac{\widetilde{Q}_{s i}}{Q_{s i}}\right)^{\left(1-\alpha_{s}-\beta_{s}\right)}
\end{aligned}
$$

as well as the aggregate output gains for each factor at a time:

$$
\begin{aligned}
& \frac{\tilde{Y}^{K}}{Y}=\prod_{s=1}^{S}\left\{\left[\frac{\sum_{i=1}^{M_{s}}\left(\tilde{Y}_{s i}^{K}\right)^{\frac{\sigma-1}{\sigma}}}{\sum_{i=1}^{M_{s}}\left(Y_{s i}\right)^{\frac{\sigma-1}{\sigma}}}\right]^{\frac{\sigma}{\sigma-1}}\right\}^{\theta_{s}} \\
& \frac{\tilde{Y}^{H}}{Y}=\prod_{s=1}^{S}\left\{\left[\frac{\sum_{i=1}^{M_{s}}\left(\tilde{Y}_{s i}^{H}\right)^{\frac{\sigma-1}{\sigma}}}{\sum_{i=1}^{M_{s}}\left(Y_{s i}\right)^{\frac{\sigma-1}{\sigma}}}\right]^{\frac{\sigma}{\sigma-1}}\right\} \\
& \frac{\tilde{Y}^{Q}}{Y}=\prod_{s=1}^{S}\left\{\left[\frac{\sum_{i=1}^{M_{s}}\left(\tilde{Y}_{s i}^{Q}\right)^{\frac{\sigma-1}{\sigma}}}{\sum_{i=1}^{M_{s}}\left(Y_{s i}\right)^{\frac{\sigma-1}{\sigma}}}\right]^{\frac{\sigma}{\sigma-1}}\right\}^{\theta_{s}}
\end{aligned}
$$

\section{B6 - Model with weights}

Because in our empirical application the dataset is composed of a stratified sample for some years and of census data for others, we have to use weights to make the stratified sample representative of the whole economy. Thus, for completeness, here we reproduce the theoretical formulas of Section 2 using weights ${ }^{35}$

Let $\lambda_{s i} \geq 1$ be the weight of firm $i$ in industry $s$ and $N_{s}$ be the number of firms in industry $s$ that are included in our sample, then, $M_{s}$ and $Y_{s}$ are given by:

$$
M_{s}=\sum_{i=1}^{N_{s}} \lambda_{s i}
$$

\footnotetext{
${ }^{35}$ Section 3 explains how the weights are computed.
} 


$$
Y_{s}=\left[\sum_{i=1}^{N_{s}} \lambda_{s i}\left(Y_{s i}\right)^{\frac{\sigma-1}{\sigma}}\right]^{\frac{\sigma}{\sigma-1}}
$$

Industry aggregates that appear in equation (16) are given by:

$$
\left(P_{s} Y_{s}\right)^{*}=\sum_{i=1}^{N s} \lambda_{i}\left(P_{s i} Y_{s i}\right)^{*}, K_{s}=\sum_{i=1}^{N_{s}} \lambda_{s i} K_{s i}, H_{s}=\sum_{i=1}^{N_{s}} \lambda_{s i} H_{s i} \text { and } Q_{s}=\sum_{i=1}^{N_{s}} \lambda_{s i} Q_{s i} .
$$

The expression for $T F P R_{s}^{*}$ (equation (18)) is now:

$$
\operatorname{TFPR}_{s}^{*}=\frac{\left(P_{s} Y_{s}\right)^{*}}{\left(K_{s}^{\alpha_{s}} H_{s}^{\beta_{s}} Q_{s}^{1-\alpha_{s}-\beta_{s}}\right)}=\frac{\sum_{i=1}^{N s} \lambda_{i}\left(P_{s i} Y_{s i}\right)^{*}}{\left(K_{s}^{\alpha_{s}} H_{s}^{\beta_{s}} Q_{s}^{1-\alpha_{s}-\beta_{s}}\right)}=\left[\frac{\sum_{i=1}^{N s} \lambda_{i}\left(A_{s i}\right)^{\sigma-1}}{\left(K_{s}^{\alpha_{s}} H_{s}^{\beta_{s}} Q_{s}^{1-\alpha_{s}-\beta_{s}}\right)}\right]^{\frac{1}{\sigma}}
$$

while industry and economy gross output reallocation gains (equations (19) and (20)) are computed from:

$$
\begin{aligned}
& \frac{Y_{s}^{*}}{Y_{s}}=\frac{\left[\sum_{i=1}^{N_{s}} \lambda_{s i}\left(Y_{s i}^{*}\right)^{\frac{\sigma-1}{\sigma}}\right]^{\frac{\sigma}{\sigma-1}}}{\left[\sum_{i=1}^{N_{s}} \lambda_{s i}\left(Y_{s i}\right)^{\frac{\sigma-1}{\sigma}}\right]^{\frac{\sigma}{\sigma-1}}}=\left[\frac{\sum_{i=1}^{N_{s}} \lambda_{s i}\left(A_{s i}\right)^{\sigma-1}}{\sum_{i=1}^{N_{s}} \lambda_{s i}\left(A_{s i} \frac{T F P R_{s}^{*}}{T F P R_{s i}}\right)^{\sigma-1}}\right]^{\frac{\sigma}{\sigma-1}} \\
& \frac{Y^{*}}{Y}=\prod_{s=1}^{S}\left\{\frac{Y_{s}^{*}}{Y_{s}}\right\}^{\theta_{s}}=\prod_{s=1}^{S}\left\{\left[\frac{\sum_{i=1}^{N_{s}} \lambda_{s i}\left(A_{s i}\right)^{\sigma-1}}{\sum_{i=1}^{N_{s}} \lambda_{s i}\left(A_{s i} \frac{T F P R_{s}^{*}}{T F P R_{s i}}\right)^{\sigma-1}}\right]^{\frac{\sigma}{\sigma-1}}\right\}^{\theta_{s}}
\end{aligned}
$$

\section{References}

Acemoglu, D. and Zilibotti, F. (1997), 'Was Prometheus unbound by chance? Risk, diversification, and growth', Journal of Political Economy 105(4), 709-51.

Amador, J. and Soares, A. C. (2013), Competition in the portuguese economy: Estimated price-cost margins under imperfect labour markets, Working Paper 8, Banco de Portugal. 
Baele, L., Ferrando, A., Hördahl, P., Krylova, E. and Monnet, C. (2004), Measuring financial integration in the euro area, Occasional Paper Series 14, European Central Bank.

Bellone, F. and Mallen-Pisano, J. (2013), Is misallocation higher in France than in the United States?, GREDEG Working Papers 2013-38, Groupe de REcherche en Droit, Économie, Gestion (GREDEG CNRS), University of Nice-Sophia Antipolis.

Benjamin, D. and Meza, F. (2009), 'Total factor productivity and labor reallocation: The case of the Korean 1997 crisis', The B.E. Journal of Macroeconomics 9(1), 1-41.

Blanchard, O. (2007), 'Adjustment within the euro. The difficult case of Portugal', Portuguese Economic Journal 6(1), 1-21.

Bonfiglioli, A. (2008), 'Financial integration, productivity and capital accumulation', Journal of International Economics 76(2), 337-355.

Boyd, J. H. and Smith, B. D. (1992), 'Intermediation and the equilibrium allocation of investment capital: Implications for economic development', Journal of Monetary Economics 30(3), 409-432.

Braguinsky, S., Branstetter, L. G. and Regateiro, A. (2011), The incredible shrinking Portuguese firm, NBER Working Paper 17265, National Bureau of Economic Research, Inc.

Buera, F. J., Kaboski, J. and Shin, Y. (2011), 'Finance and development: A tale of two sectors', American Economic Review 101(5), 1964-2002.

Busso, M., Madrigal, L. and Pagés, C. (2012), Productivity and resource misallocation in Latin America, Working Paper IDB-WP-306, Inter-American Development Bank.

Camacho, A. and Conover, E. (2010), Misallocation and productivity in Colombia's manufacturing industries, Working Paper IDB-WP-123, Inter-American Development Bank. 
Chen, K. and Irarrazabal, A. (2013), Misallocation and the recovery of manufacturing TFP after a financial crisis, Working Paper 2013/01, Norges Bank.

Christopoulou, R. and Vermeulen, P. (2012), 'Markups in the Euro area and the US over the period 1981-2004: a comparison of 50 sectors', Empirical Economics 42(1), 5377.

Duarte, M. and Restuccia, D. (2007), 'The structural transformation and aggregate productivity in Portugal', Portuguese Economic Journal 6(1), 23-46.

Duarte, M. and Restuccia, D. (2010), 'The role of the structural transformation in aggregate productivity', The Quarterly Journal of Economics 125(1), 129-173.

Edison, H. J., Levine, R., Ricci, L. and Slok, T. (2002), 'International financial integration and economic growth', Journal of International Money and Finance 21(6), 749776.

Eichengreen, B. (2001), 'Capital account liberalization: What do cross-country studies tell us?', The world bank economic review 15(3), 341-365.

Foster, L., Grim, C. and Haltiwanger, J. (2013), Reallocation in the Great Recession: Cleansing or Not?, Paper No. CES-WP- 13-42, US Census Bureau Center for Economic Studies.

Ghandi, A., Navarro, S. and Rivers, D. (2011), On the identification of production functions: How heterogenous is productivity, Working Paper Series, CIBC.

Hallward-Driemeier, M. and Rijkers, B. (2011), Do crises catalyze creative destruction? Firm-level evidence from Indonesia, Policy Research Working Paper Series 5869, The World Bank.

Hsieh, C.-T. and Klenow, P. J. (2009), 'Misallocation and manufacturing TFP in China and India', The Quarterly Journal of Economics 124(4), 1403-1448. 
Hsieh, C.-T. and Klenow, P. J. (2011), 'Misallocation and manufacturing TFP in China and India: Correction appendix', Stanford University. Unpublished .

Jones, C. I. (2013), Misallocation, economic growth and input-output economics, in D. Acemoglu, M. Arellano and E. Dekel, eds, 'Advances in Economics and Econometrics, Tenth World Congress, Applied Economics', Vol. II, Cambridge University Press, chapter 10, pp. 419-456.

Kose, M. A., Prasad, E. S. and Terrones, M. E. (2009), 'Does openness to international financial flows raise productivity growth?', Journal of International Money and Finance 28(4), 554-580.

Machicado, C. G. and Birbuet, J. C. (2012), 'Misallocation and manufacturing TFP in Bolivia during the market liberalization period', The B.E. Journal of Macroeconomics 12(1), 1-45.

Oberfield, E. (2013), 'Productivity and misallocation during a crisis: Evidence from the Chilean crisis of 1982', Review of Economic Dynamics 16(1), 100-119.

Reis, R. (2013), 'The Portuguese slump and crash and the euro crisis', Brookings Papers on Economic Activity 46(1, Spring), 143-210.

Restuccia, D. and Rogerson, R. (2008), 'Policy distortions and aggregate productivity with heterogeneous establishments', Review of Economic Dynamics 11, 707-720.

Sandleris, G. and Wright, M. L. J. (2011), The costs of financial crises: Resource misallocation, productivity and welfare in the 2001 Argentine crisis, Working Paper 17552, National Bureau of Economic Research.

Ziebarth, N. (2013), 'Are China and India backwards? Evidence from the 19th century U.S. Census of Manufactures', Review of Economic Dynamics 16(1), 86-99. 